\title{
Synthesis of the proposed isomers of the deep-sea mussel metabolites bathymodiolamides $A$ and $B$
}

Alexander Bär, Sofia I. Bär, Moritz Röder and Rainer Schobert*

Department of Chemistry, University Bayreuth, Universitaetsstrasse 30, 95440 Bayreuth, Germany;

Rainer.Schobert@uni-bayreuth.de

Table of content Page

Comparison of synthetic and isolated bathymodiolamides A and B $\quad$ S2

$\begin{array}{ll}\text { Analysis of the Mosher esters of alcohol } 4 & \text { S4 }\end{array}$

${ }^{1} \mathrm{H}$ and ${ }^{13} \mathrm{C}\left\{{ }^{1} \mathrm{H}\right\}$ NMR spectra

Cell culture conditions and inhibition of cell growth $\quad$ S32

$\begin{array}{ll}\text { References } & \text { S33 }\end{array}$ 


\section{Comparison of synthetic and isolated bathymodiolamides A (1) and B (2)}

Table 1. Comparison of ${ }^{13} \mathrm{C}\left\{{ }^{1} \mathrm{H}\right\}$ and ${ }^{1} \mathrm{H}$ NMR shifts of isolated and synthetic Bathymodiolamides A (1) and B (2)
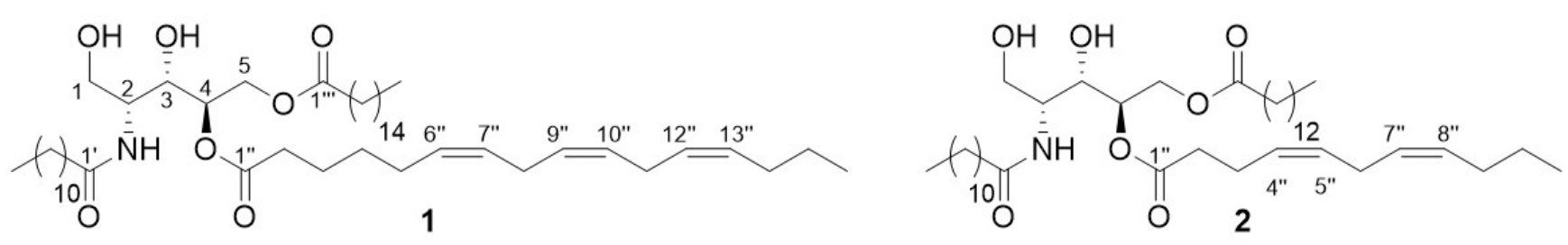

\begin{tabular}{|c|c|c|c|c|c|c|c|c|}
\hline & \multicolumn{2}{|c|}{ natural 1 in $\mathrm{CD}_{3} \mathrm{OD}^{1}$} & \multicolumn{2}{|c|}{ synthetic 1 in $\mathrm{CD}_{3} \mathrm{OD}$} & \multicolumn{2}{|c|}{ natural 2 in $\mathrm{CD}_{3} \mathrm{OD}^{1}$} & \multicolumn{2}{|c|}{ synthetic $\mathbf{2}$ in $\mathrm{CD}_{3} \mathrm{OD}$} \\
\hline Pos. & $\delta_{c}$ & $\delta_{\mathrm{H}}$ (mult., $\left.J[\mathrm{~Hz}]\right)$ & $\delta_{c}$ & $\delta_{\mathrm{H}}$ (mult., $J[\mathrm{~Hz}]$ ) & $\delta_{c}$ & $\delta_{\mathrm{H}}$ (mult., $\left.J[\mathrm{~Hz}]\right)$ & $\delta_{c}$ & $\delta_{\mathrm{H}}($ mult., $J[\mathrm{~Hz}])$ \\
\hline $1 \mathrm{a}$ & 63.7 & $3.64(d, 4.5)$ & 62.5 & $3.61(d d, 10.7,8.2)$ & 63.7 & $3.65(d, 4.5)$ & 62.5 & $3.61(\mathrm{dd}, 10.7,8.5)$ \\
\hline $1 b$ & & $3.65(d, 4.5)$ & & $3.53(\mathrm{dd}, 10.7,5.8)$ & & $3.65(d, 4.5)$ & & $3.53(\mathrm{dd}, 10.7,5.8)$ \\
\hline 2 & 53.3 & $4.29(\mathrm{dd}, 4.5,2)$ & 51.9 & $4.12-4.09(\mathrm{~m})$ & 53.5 & $4.29(\mathrm{dd}, 4.5,2)$ & 51.9 & $4.12-4.09(\mathrm{~m})$ \\
\hline 3 & 62.5 & $4.01(\mathrm{dd}, 6.5,2)$ & 68.2 & $4.04(d d(9.5,1.5)$ & 62.5 & $4.01(d d, 6.5,2)$ & 68.2 & 4.05 (dd $(9.5,1.5)$ \\
\hline 4 & 66.1 & $5.25(\mathrm{dt}, 6.5,3)$ & 71.8 & $4.92-4.89(\mathrm{~m})$ & 66.1 & $5.25(\mathrm{dt}, 6.5,3)$ & 71.9 & $4.93-4.89(\mathrm{~m})$ \\
\hline $5 a$ & 59.9 & $4.20(\mathrm{dd}, 12,3)$ & 64.2 & 4.12 (dd $(12.1,5.8)$ & 59.9 & $4.20(\mathrm{dd}, 12,3)$ & 64.2 & $4.14(\mathrm{dd}, 12.2,5.8)$ \\
\hline $5 b$ & & $4.45(\mathrm{dd}, 12,3)$ & & $4.62(\mathrm{dd}, 12.1,2.3)$ & & $4.45(d d, 12,3)$ & & $4.60(\mathrm{dd}, 12.2,2.4)$ \\
\hline $1^{\prime}$ & 173.2 & & 176.5 & & 173.2 & & 176.5 & \\
\hline $2^{\prime}$ & 30.0 & $2.31(t, 7.5)$ & 33.3 & $2.22-2.15(\mathrm{~m})$ & 30.0 & $2.31(t, 7.5)$ & 37.3 & $2.24-2.13(\mathrm{~m})$ \\
\hline $3^{\prime}$ & 29.9 & 1.29 (brs) & 31.0 & $1.68-1.55(\mathrm{~m})$ & 29.9 & 1.29 (brs) & 26.2 & $1.61-1.57(\mathrm{~m})$ \\
\hline $4^{\prime}$ & 29.8 & 1.29 (brs) & 31.0 & $1.36-1.25(\mathrm{~m})$ & 29.8 & 1.29 (brs) & 30.8 & $1.35-1.26(\mathrm{~m})$ \\
\hline $5^{\prime}$ & 29.8 & 1.29 (brs) & 31.0 & $1.36-1.25(\mathrm{~m})$ & 29.8 & 1.29 (brs) & 30.8 & $1.35-1.26(\mathrm{~m})$ \\
\hline $6^{\prime}$ & 29.8 & 1.29 (brs) & 31.0 & $1.36-1.25(\mathrm{~m})$ & 29.8 & 1.29 (brs) & 30.8 & $1.35-1.26(\mathrm{~m})$ \\
\hline $7^{\prime}$ & 29.7 & 1.29 (brs) & 30.8 & $1.36-1.25(\mathrm{~m})$ & 29.7 & 1.29 (brs) & 30.7 & $1.35-1.26(\mathrm{~m})$ \\
\hline $8^{\prime}$ & 29.7 & 1.29 (brs) & 30.8 & $1.36-1.25(\mathrm{~m})$ & 29.7 & 1.29 (brs) & 30.6 & $1.35-1.26(\mathrm{~m})$ \\
\hline $9^{\prime}$ & 29.5 & 1.29 (brs) & 30.5 & $1.36-1.25(\mathrm{~m})$ & 29.5 & 1.29 (brs) & 30.6 & $1.35-1.26(\mathrm{~m})$ \\
\hline $10^{\prime}$ & 29.5 & 1.29 (brs) & 30.5 & $1.36-1.25(\mathrm{~m})$ & 29.5 & 1.29 (brs) & 30.5 & $1.35-1.26(\mathrm{~m})$ \\
\hline $11^{\prime}$ & 28.9 & 1.29 (brs) & 23.9 & $1.36-1.25(\mathrm{~m})$ & 28.9 & 1.29 (brs) & 30.4 & $1.35-1.26(\mathrm{~m})$ \\
\hline $12^{\prime}$ & 13.2 & $0.89(t, 7.0)$ & 14.7 & $0.90(t, 7.3)$ & 13.2 & $0.89(t, 7.0)$ & 14.7 & $0.90(t, 7.3)$ \\
\hline $1^{\prime \prime}$ & 173.4 & & 174.1 & & 173.4 & & 173.6 & \\
\hline $2^{\prime \prime}$ & 30.1 & $2.35(t, 7.2)$ & 35.2 & $2.38-2.37(\mathrm{~m})$ & 30.1 & $2.35(t, 7.2)$ & 35.3 & $2.42-2.32(\mathrm{~m})$ \\
\hline
\end{tabular}




\begin{tabular}{|c|c|c|c|c|c|c|c|c|}
\hline $3 "$ & 22.5 & $1.68(\mathrm{~m})$ & 30.4 & $1.68-1.55(\mathrm{~m})$ & 24.5 & $2.08(\mathrm{~m})$ & 23.8 & $2.42-2.32(\mathrm{~m})$ \\
\hline $4^{\prime \prime}$ & 27.5 & $1.33(\mathrm{~m})$ & 28.2 & $1.45-1.36(\mathrm{~m})$ & 127.5 & $5.38(\mathrm{~m})$ & 131.1 & $5.41-5.32(\mathrm{~m})$ \\
\hline $5 "$ & 24.5 & $2.08(\mathrm{~m})$ & 26.2 & $2.09-2.02(\mathrm{~m})$ & 128.1 & $5.36(\mathrm{~m})$ & 131.1 & $5.41-5.32(\mathrm{~m})$ \\
\hline 6" & 129.5 & $5.38(\mathrm{~m})$ & 131.1 & $5.42-5.32(\mathrm{~m})$ & 26.5 & $2.81(\mathrm{~m})$ & 26.7 & $2.84-2.82(\mathrm{~m})$ \\
\hline $7^{\prime \prime}$ & 127.8 & $5.36(\mathrm{~m})$ & 129.3 & $5.42-5.32(\mathrm{~m})$ & 127.9 & $5.36(\mathrm{~m})$ & 130.5 & $5.41-5.32(\mathrm{~m})$ \\
\hline $8^{\prime \prime}$ & 26.5 & $2.81(\mathrm{~m})$ & 27.1 & $2.84-2.82(\mathrm{~m})$ & 128.1 & $5.36(\mathrm{~m})$ & 129.2 & $5.41-5.32(\mathrm{~m})$ \\
\hline $9 " 1$ & 127.9 & $5.36(\mathrm{~m})$ & 129.5 & $5.42-5.32(\mathrm{~m})$ & 26.5 & $2.01(\mathrm{~m})$ & 30.4 & $2.07(q, 6.7)$ \\
\hline $10^{\prime \prime}$ & 128.1 & $5.36(\mathrm{~m})$ & 129.4 & $5.42-5.32(\mathrm{~m})$ & 22.5 & $1.40(\mathrm{~m})$ & 23.9 & $1.44-1.36(\mathrm{~m})$ \\
\hline $11^{\prime \prime}$ & 26.5 & $2.81(\mathrm{~m})$ & 26.8 & $2.84-2.82(\mathrm{~m})$ & 13.1 & $0.91(t, 7.5)$ & 14.4 & $0.93(t, 7.3)$ \\
\hline $12^{\prime \prime}$ & 128.0 & $5.36(\mathrm{~m})$ & 129.2 & $5.42-5.32(\mathrm{~m})$ & & & & \\
\hline $13^{\prime \prime}$ & 128.4 & $5.36(\mathrm{~m})$ & 130.9 & $5.42-5.32(\mathrm{~m})$ & & & & \\
\hline $14^{\prime \prime}$ & 25.5 & $2.01(\mathrm{~m})$ & 25.6 & $2.09-2.02(\mathrm{~m})$ & & & & \\
\hline $15^{\prime \prime}$ & 22.5 & $1.40(\mathrm{~m})$ & 24.1 & $1.45-1.36(\mathrm{~m})$ & & & & \\
\hline $16^{\prime \prime}$ & 13.1 & $0.91(\mathrm{~m})$ & 14.4 & $0.93(t, 7.3)$ & & & & \\
\hline $1^{\prime \prime \prime}$ & 173.8 & & 175.3 & & 173.8 & & 175.3 & \\
\hline $2^{\prime \prime \prime}$ & 30.2 & $2.36(t, 7.5)$ & 37.3 & $2.38-2.37(\mathrm{~m})$ & 30.2 & $2.36(t, 7.5)$ & 35.3 & $2.30(t, 7.3)$ \\
\hline $3^{\prime \prime \prime}$ & 29.9 & 1.29 (brs) & 31.0 & $1.68-1.55(\mathrm{~m})$ & 29.9 & 1.29 (brs) & 27.2 & $1.61-1.57(\mathrm{~m})$ \\
\hline $4^{\prime \prime \prime}$ & 29.8 & 1.29 (brs) & 31.0 & $1.36-1.25(\mathrm{~m})$ & 29.8 & 1.29 (brs) & 30.8 & $1.35-1.26(\mathrm{~m})$ \\
\hline $5^{\prime \prime \prime}$ & 29.8 & 1.29 (brs) & 31.0 & $1.36-1.25(\mathrm{~m})$ & 29.8 & 1.29 (brs) & 30.8 & $1.35-1.26(\mathrm{~m})$ \\
\hline $6^{\prime \prime \prime}$ & 29.8 & 1.29 (brs) & 30.8 & $1.36-1.25(\mathrm{~m})$ & 29.8 & 1.29 (brs) & 30.8 & $1.35-1.26(\mathrm{~m})$ \\
\hline $7^{\prime \prime \prime}$ & 29.7 & 1.29 (brs) & 30.8 & $1.36-1.25(\mathrm{~m})$ & 29.7 & 1.29 (brs) & 30.8 & $1.35-1.26(\mathrm{~m})$ \\
\hline $8^{\prime \prime \prime}$ & 29.7 & 1.29 (brs) & 30.7 & $1.36-1.25(\mathrm{~m})$ & 29.7 & 1.29 (brs) & 30.7 & $1.35-1.26(\mathrm{~m})$ \\
\hline $9^{\prime \prime \prime}$ & 29.6 & 1.29 (brs) & 30.6 & $1.36-1.25(\mathrm{~m})$ & 29.6 & 1.29 (brs) & 30.7 & $1.35-1.26(\mathrm{~m})$ \\
\hline $10^{\prime \prime \prime}$ & 29.6 & 1.29 (brs) & 30.6 & $1.36-1.25(\mathrm{~m})$ & 29.6 & 1.29 (brs) & 30.6 & $1.35-1.26(\mathrm{~m})$ \\
\hline $11^{\prime \prime \prime}$ & 29.5 & 1.29 (brs) & 30.5 & $1.36-1.25(\mathrm{~m})$ & 29.5 & 1.29 (brs) & 30.5 & $1.35-1.26(\mathrm{~m})$ \\
\hline $12^{\prime \prime \prime}$ & 29.5 & 1.29 (brs) & 30.5 & $1.36-1.25(\mathrm{~m})$ & 29.5 & 1.29 (brs) & 30.4 & $1.35-1.26(\mathrm{~m})$ \\
\hline $13^{\prime \prime \prime}$ & 29.5 & 1.29 (brs) & 30.5 & $1.36-1.25(\mathrm{~m})$ & 28.4 & 1.29 (brs) & 30.4 & $1.35-1.26(\mathrm{~m})$ \\
\hline $14^{\prime \prime \prime}$ & 29.4 & 1.29 (brs) & 30.5 & $1.36-1.25(\mathrm{~m})$ & 13.0 & $0.90(t, 7.5)$ & 14.7 & $0.90(t, 7.3)$ \\
\hline $15^{\prime \prime \prime}$ & 28.9 & 1.29 (brs) & 23.9 & $1.36-1.25(\mathrm{~m})$ & & & & \\
\hline $16^{\prime \prime \prime}$ & 13.0 & $0.90(t, 7.5)$ & 14.7 & $0.90(t, 7.3)$ & & & & \\
\hline
\end{tabular}


Analysis of the Mosher esters of alcohol 4 (according to literature ${ }^{2}$ )

Scheme 1. Synthesis of the TBS-ether of alcohol 4 and of the $S$ - and $R$-Mosher esters as well as $\Delta \delta_{S R}=\delta_{S}-\delta_{R}$ values in $\mathrm{Hz}$ calculated from their ${ }^{1} \mathrm{H}$ NMR spectra.
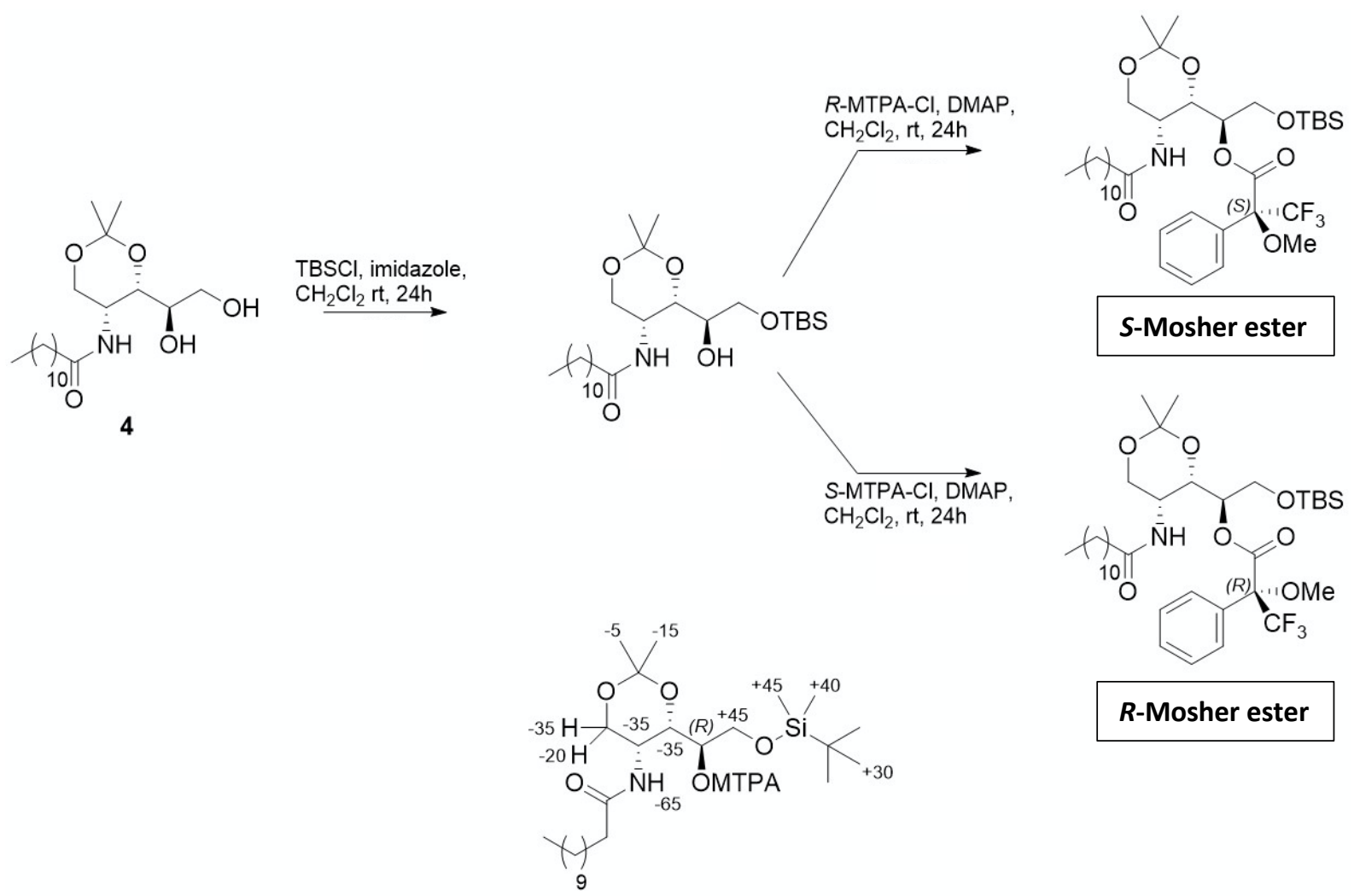

$\boldsymbol{R}$-Mosher ester

\begin{tabular}{|l|l|l|l|}
\hline position & $\boldsymbol{\delta}_{\boldsymbol{S}}$ (in ppm) & $\boldsymbol{\delta}_{\boldsymbol{R}}$ (in ppm) & $\boldsymbol{\Delta} \boldsymbol{\delta}_{\text {RR }}$ (in $\left.\mathbf{H z}\right)$ \\
\hline $\mathbf{4}$ & 4.32 & 4.39 & -35 \\
\hline $\mathbf{5}$ & 3.88 & 3.95 & -35 \\
\hline $\mathbf{6 a}$ & 3.97 & 4.01 & -20 \\
\hline $\mathbf{6 b}$ & 3.73 & 3.80 & -35 \\
\hline $\mathbf{2}-\mathrm{CH}_{\mathbf{3}} \mathbf{a}$ & 1.46 & 1.47 & -5 \\
\hline $\mathbf{2}-\mathrm{CH}_{3} \mathbf{b}$ & 1.40 & 1.43 & -15 \\
\hline $\mathbf{N H}$ & 6.00 & 6.13 & -65 \\
\hline $\mathbf{1}^{\mathbf{\prime}}$ & 5.20 & 5.14 & \\
\hline $\mathbf{2}$ & 3.82 & 3.73 & +45 \\
\hline $\mathbf{S i}-\mathbf{C H}_{\mathbf{3}} \mathbf{a}$ & 0.07 & -0.01 & +40 \\
\hline $\mathbf{S i C H} \mathbf{b}$ & 0.06 & -0.03 & +45 \\
\hline $\mathbf{S i C}\left(\mathbf{C H}_{\mathbf{3}}\right)_{\mathbf{3}}$ & 0.89 & 0.83 & +30 \\
\hline
\end{tabular}


${ }^{1} \mathrm{H}$ and ${ }^{13} \mathrm{C}\left\{{ }^{1} \mathrm{H}\right\}$ NMR spectra

$\overbrace{\substack{\mathrm{Boc} \\ 6}}^{\mathrm{OH}}$
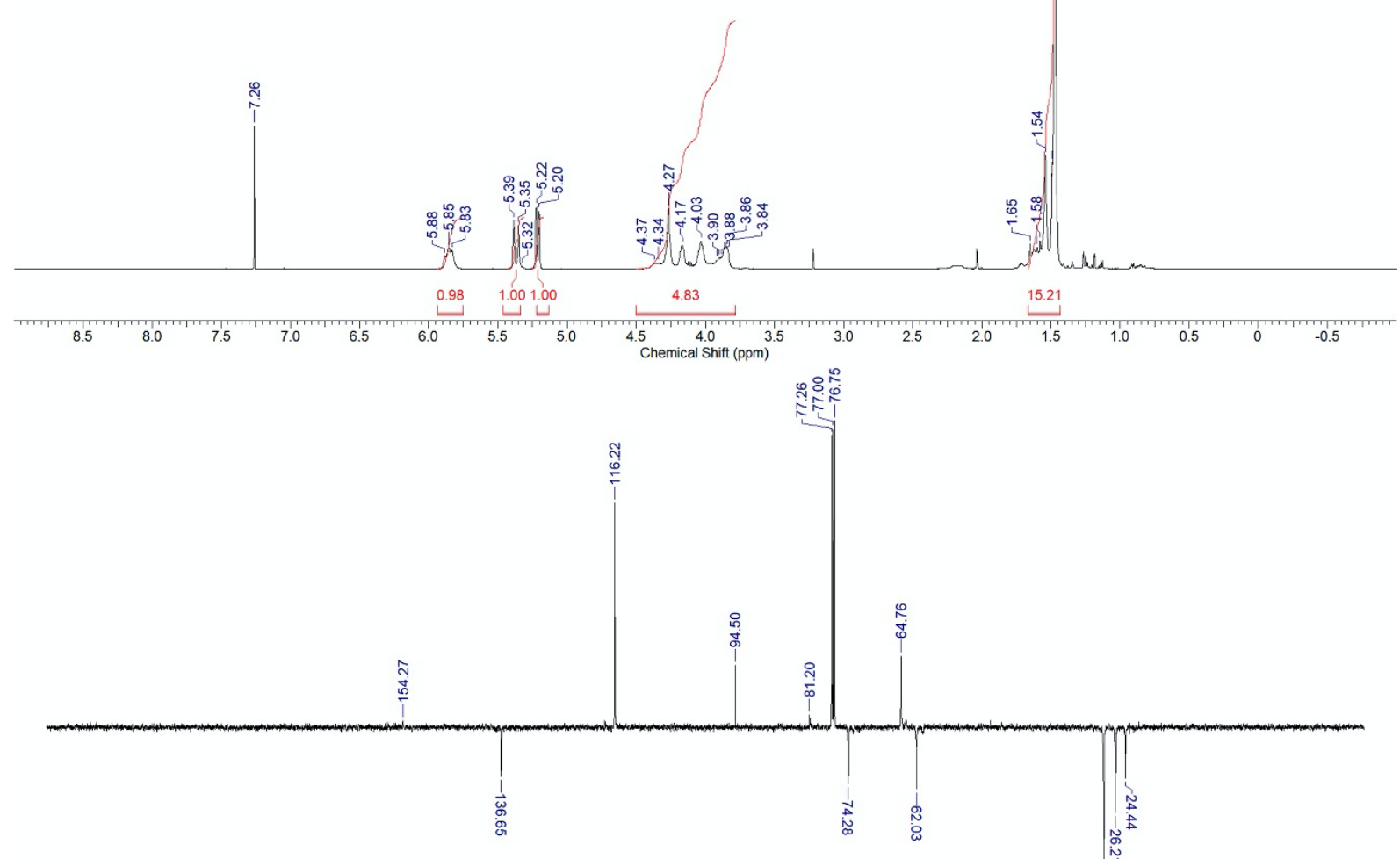

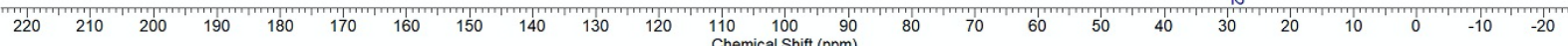



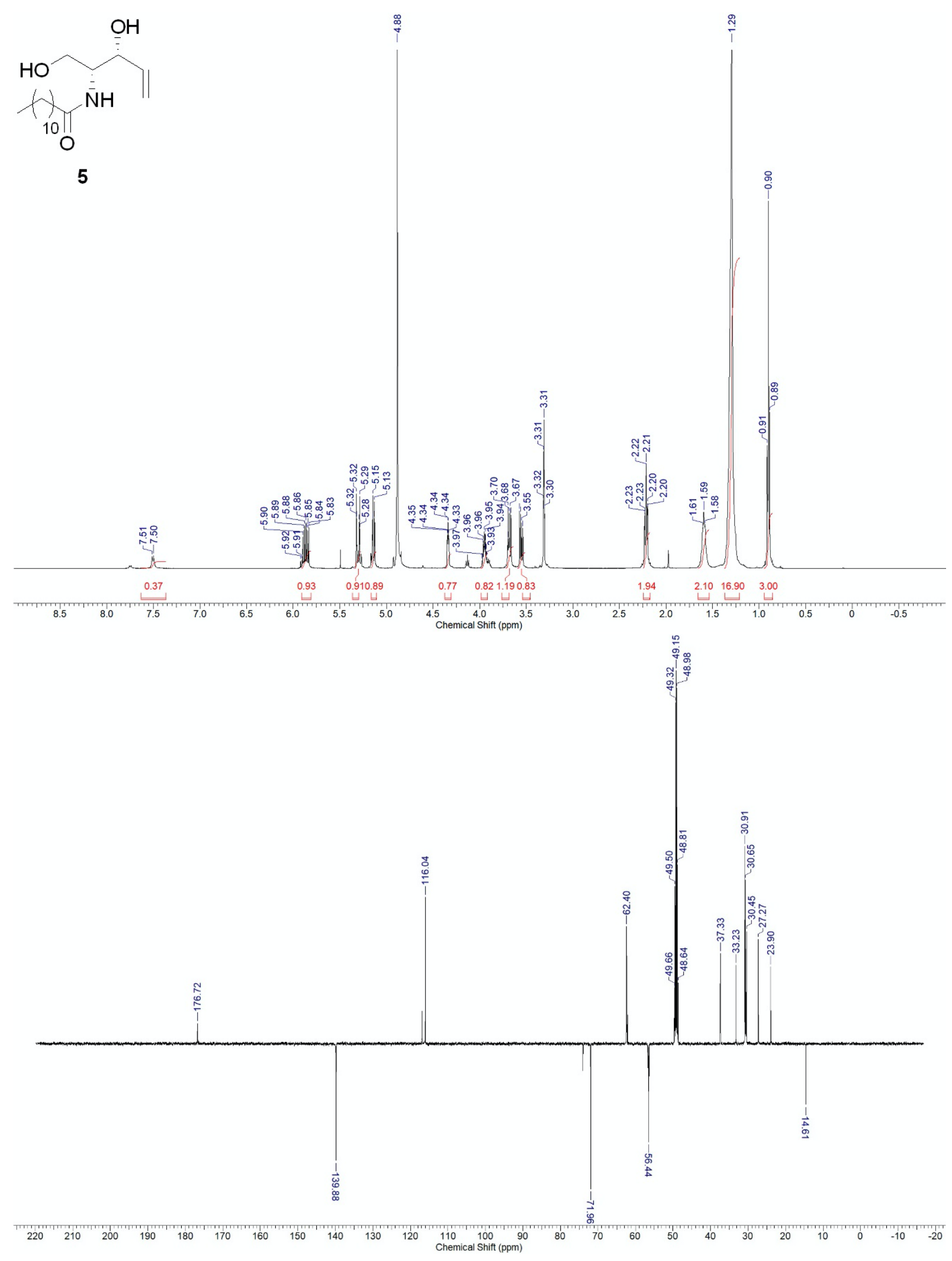

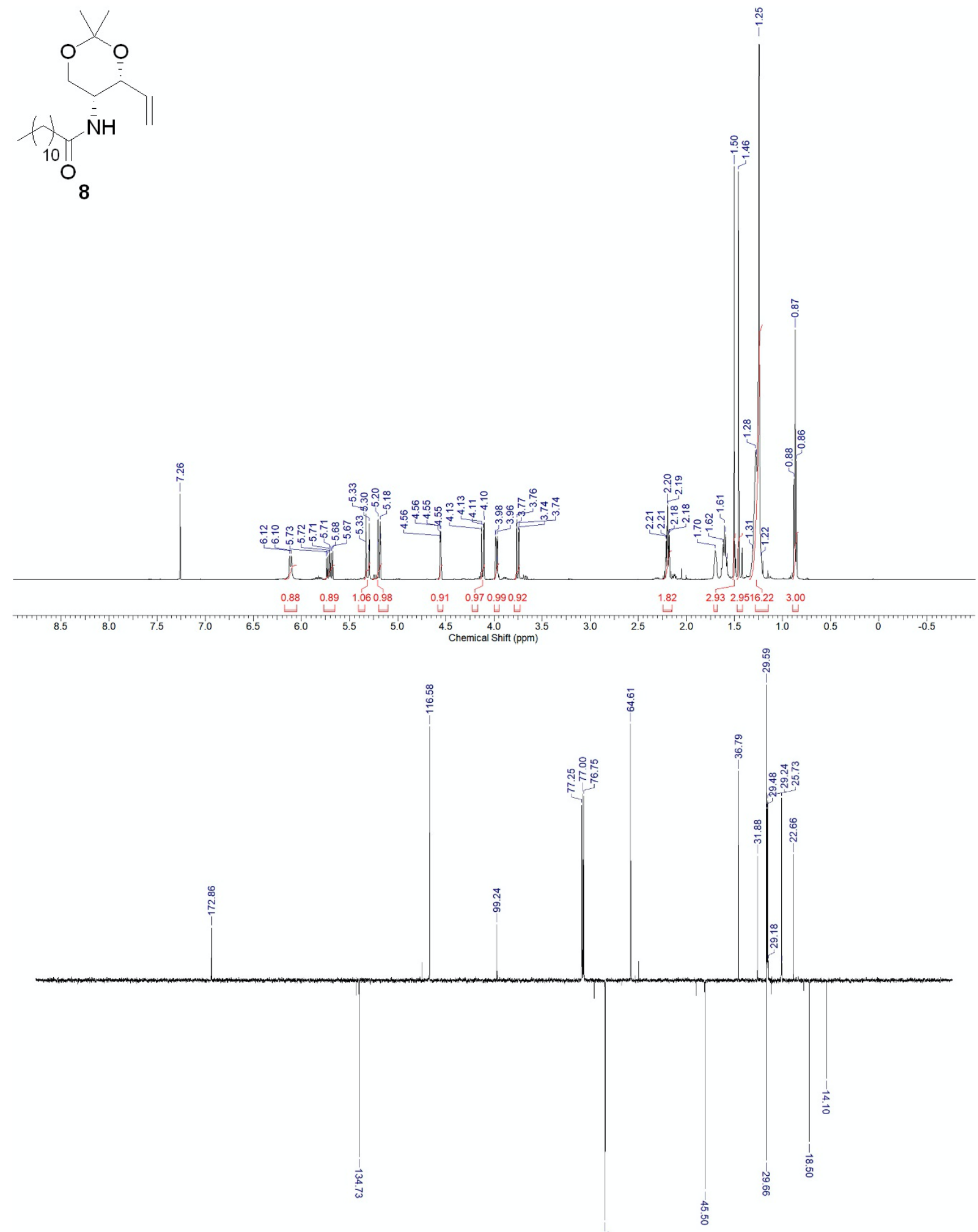

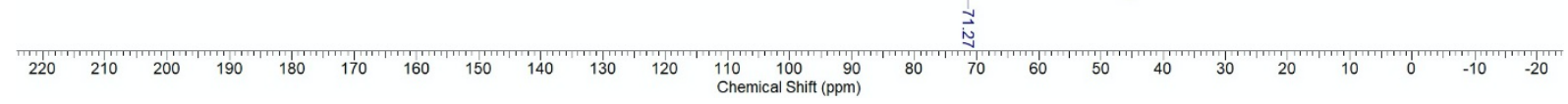



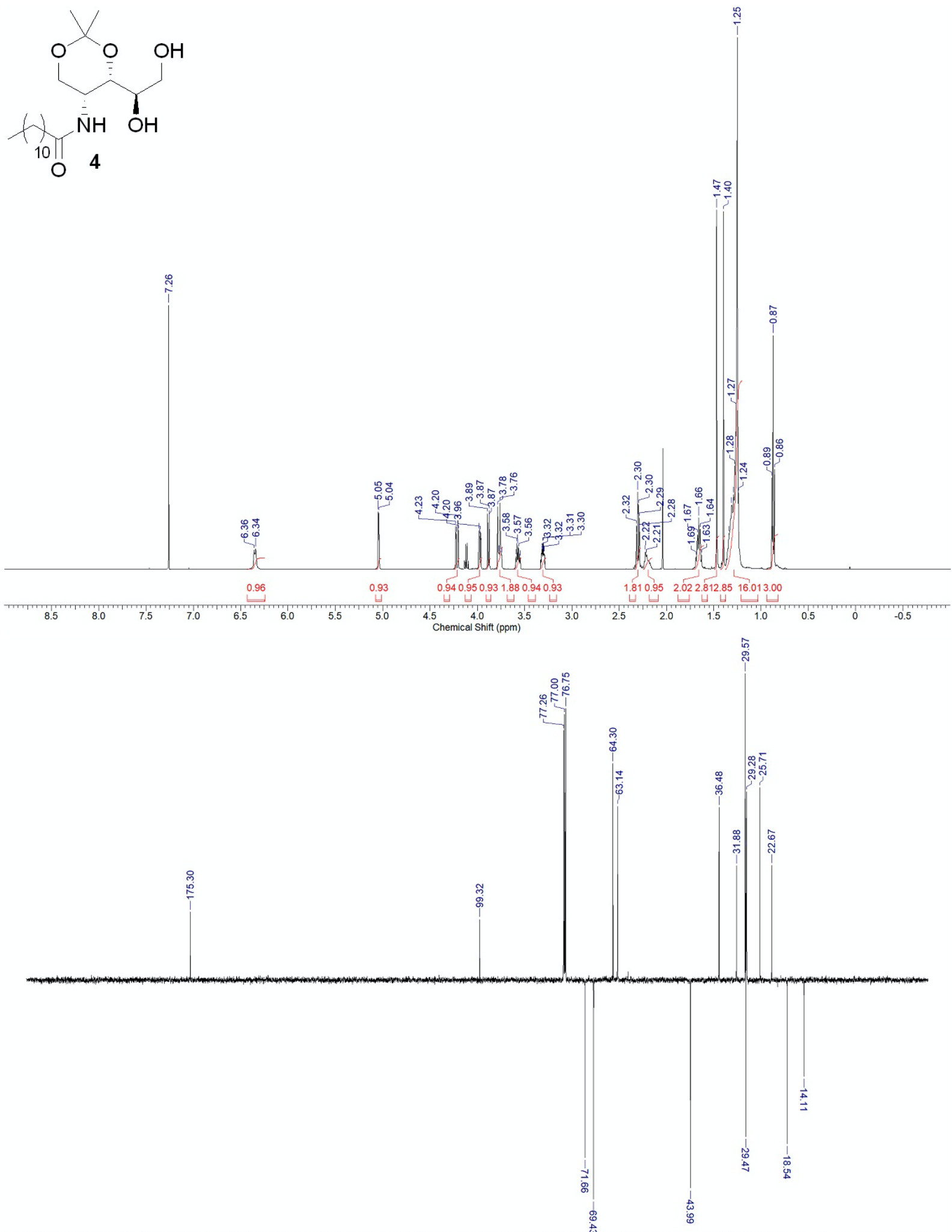

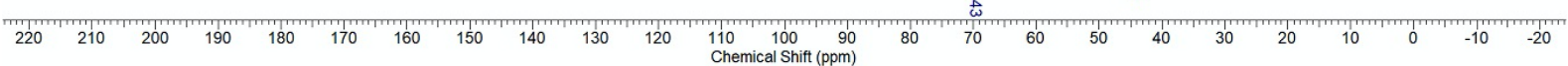



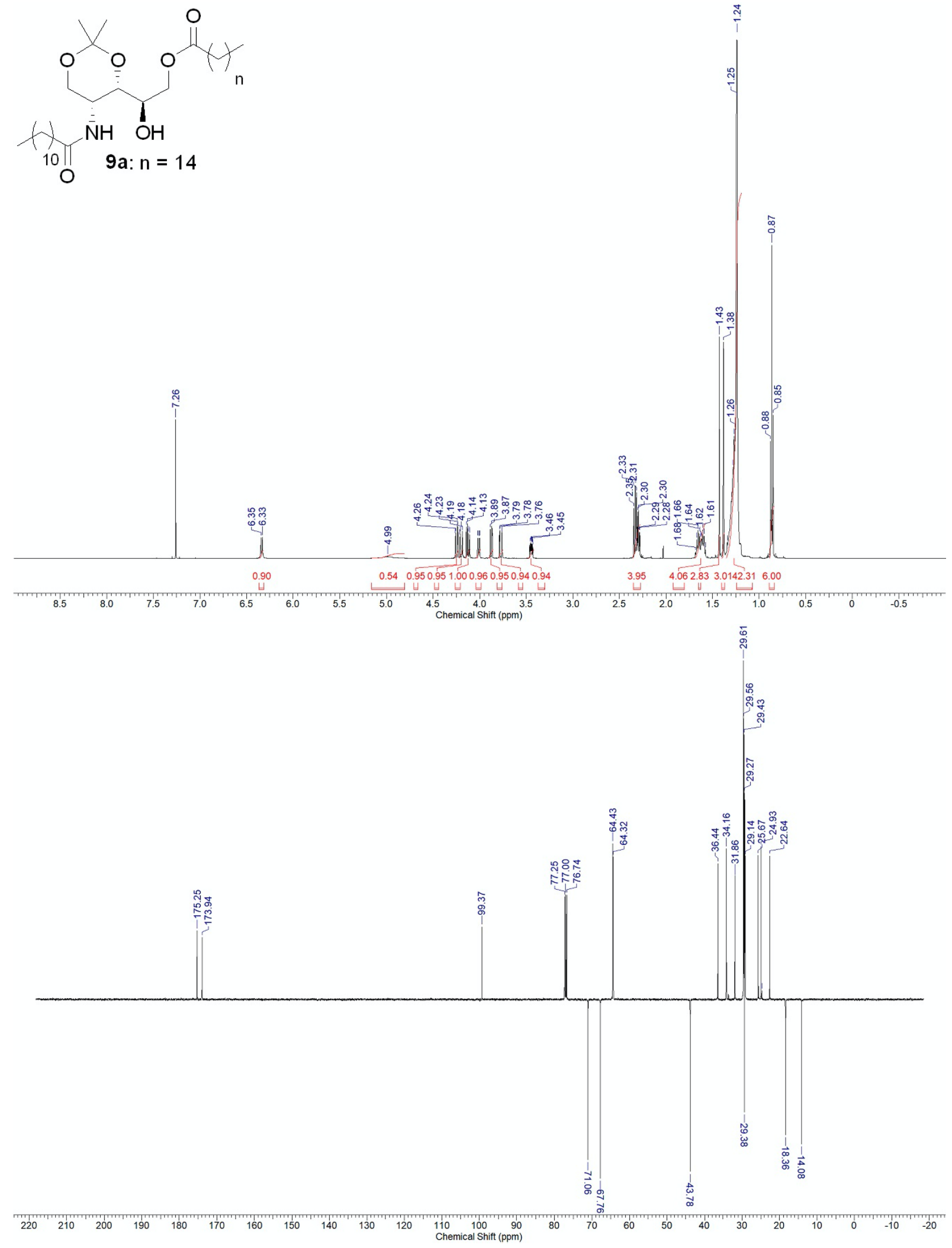


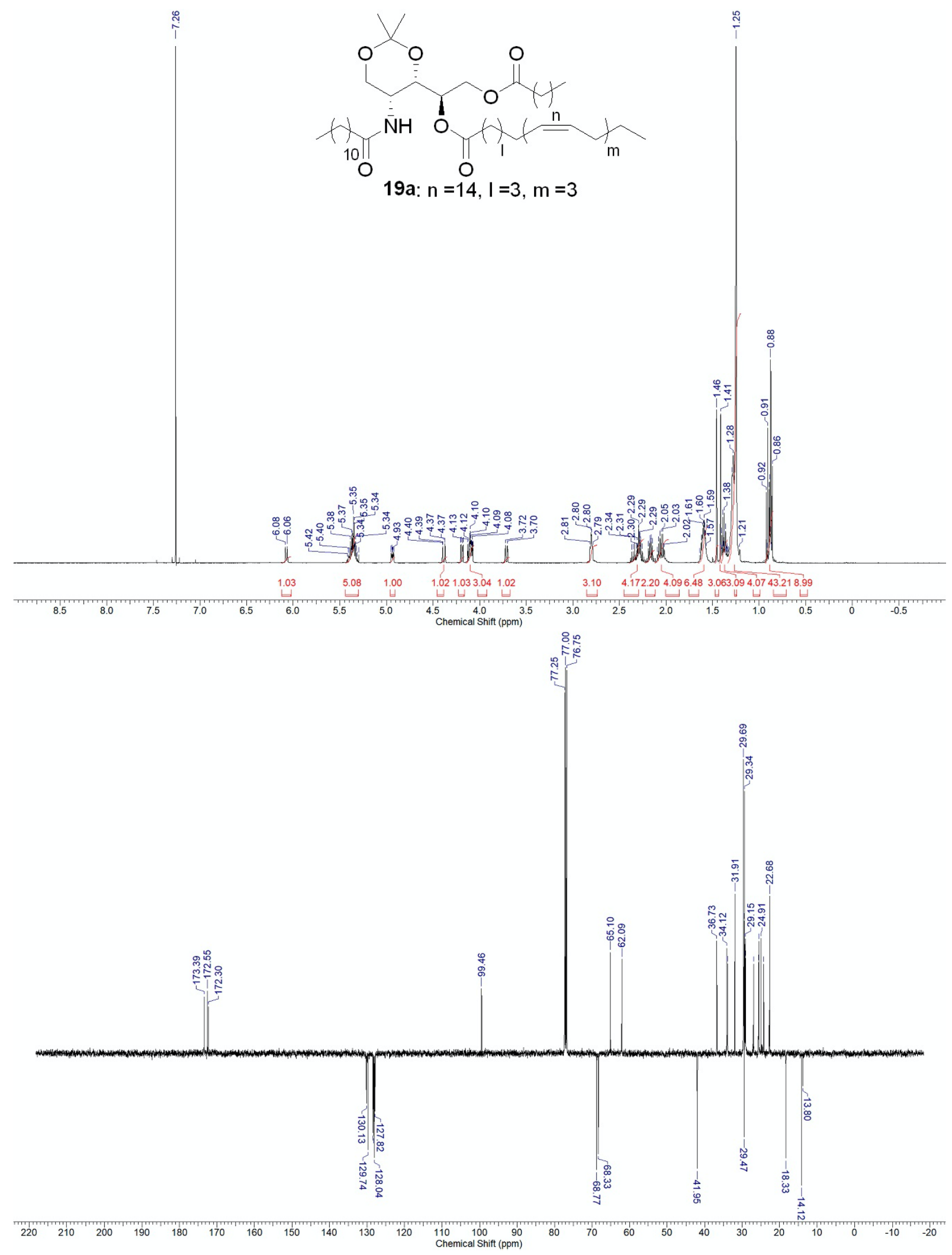



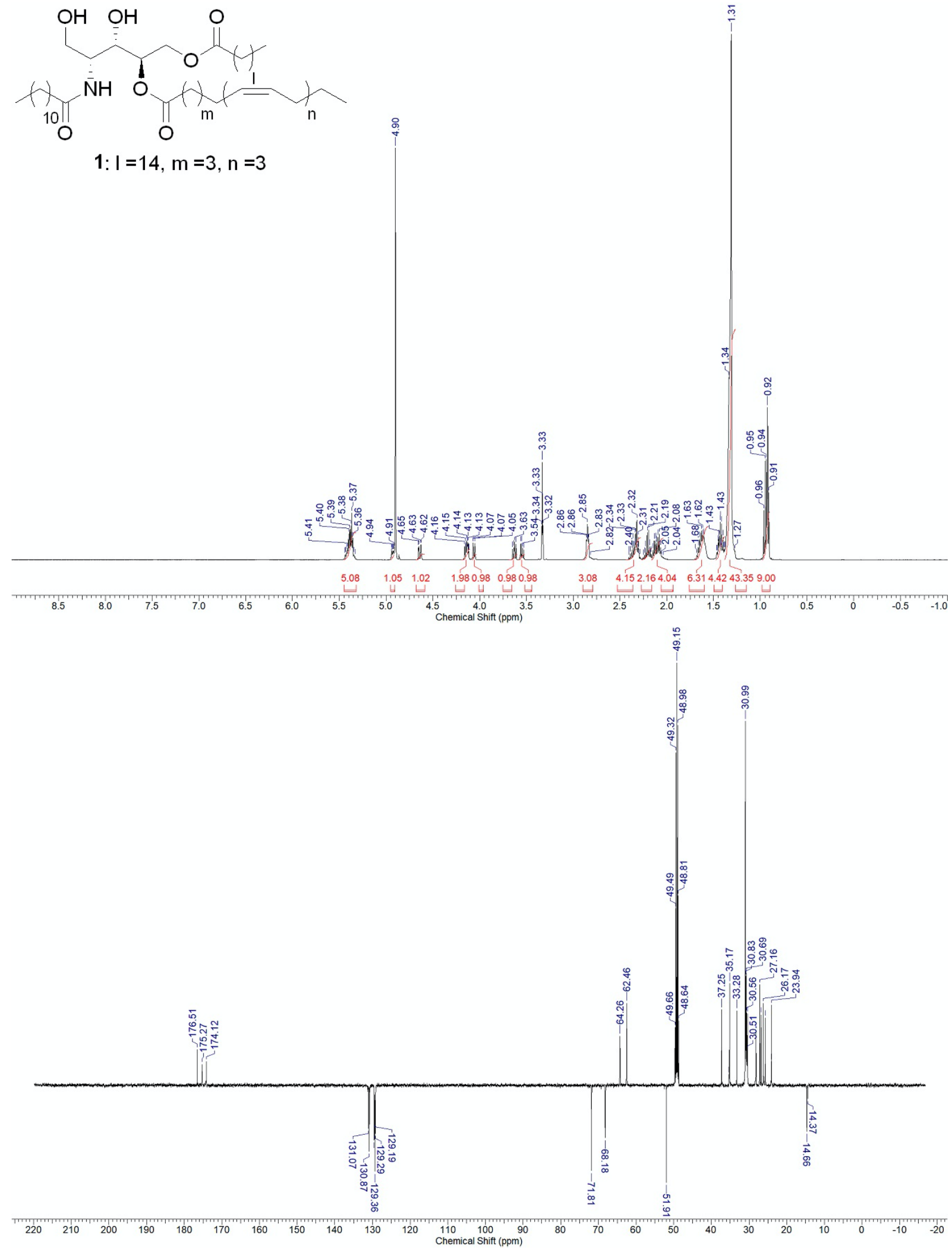
COSY of 1

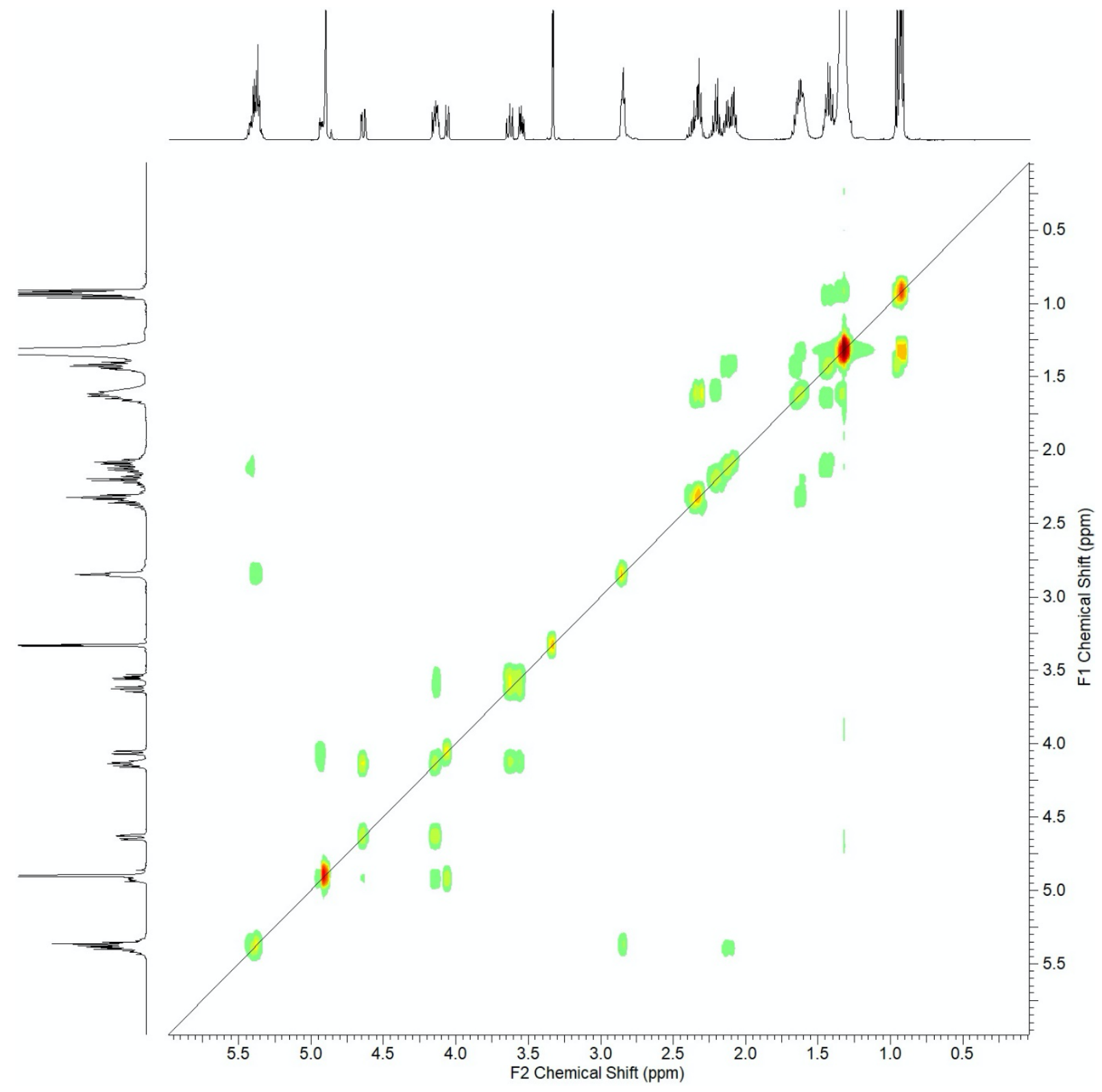


$\mathrm{HMBC}$ of 1

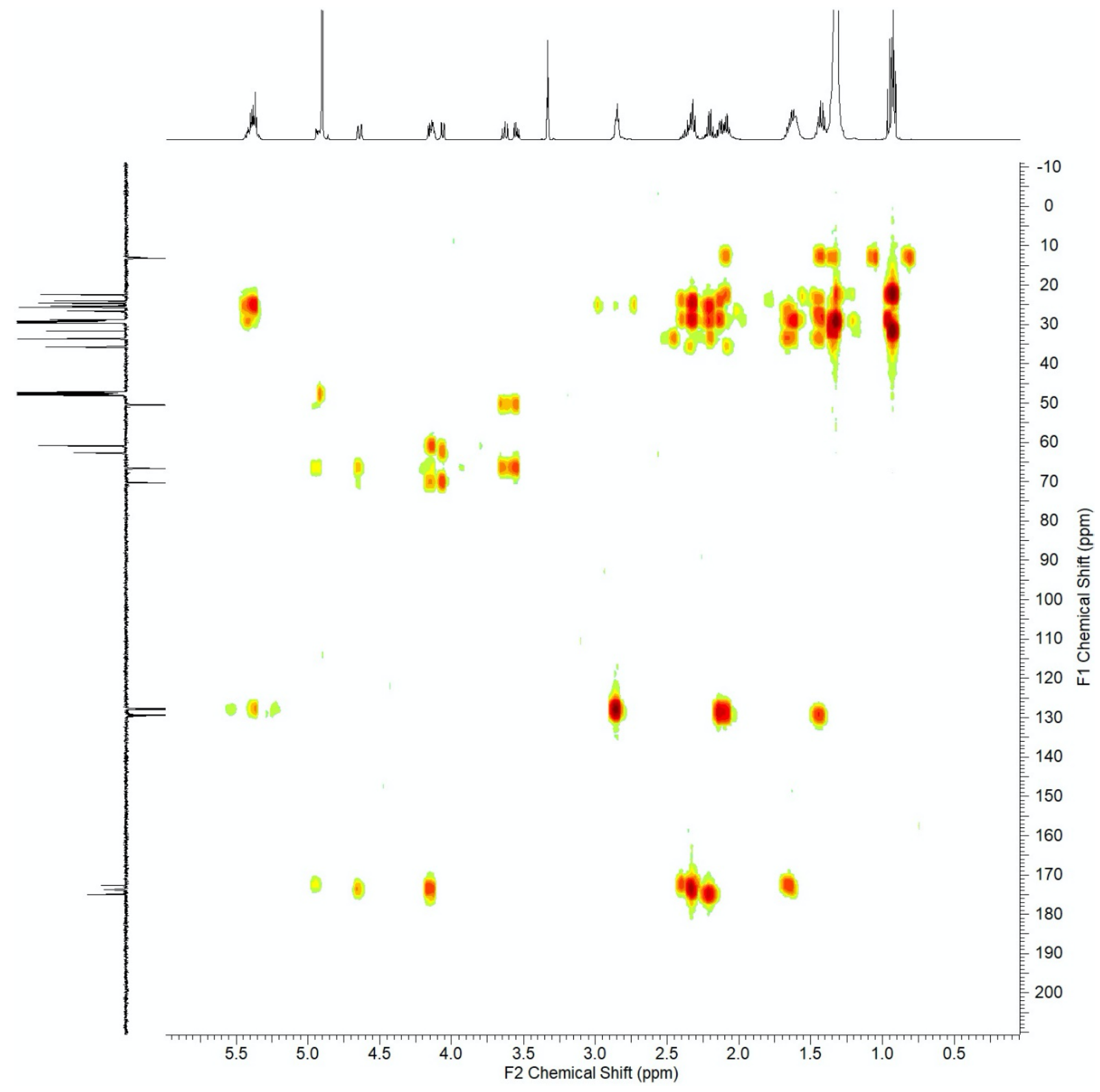


HSQC of 1

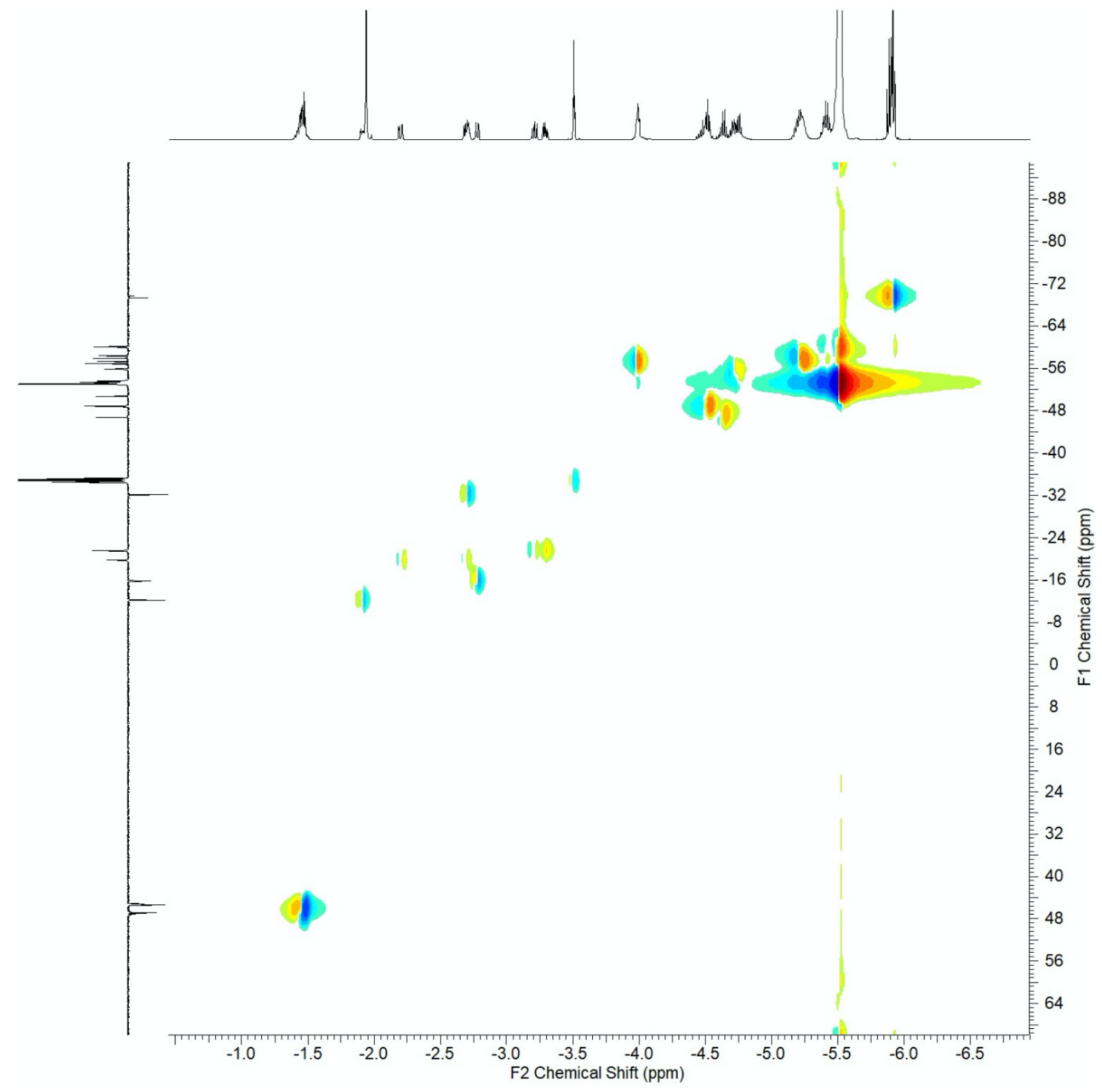



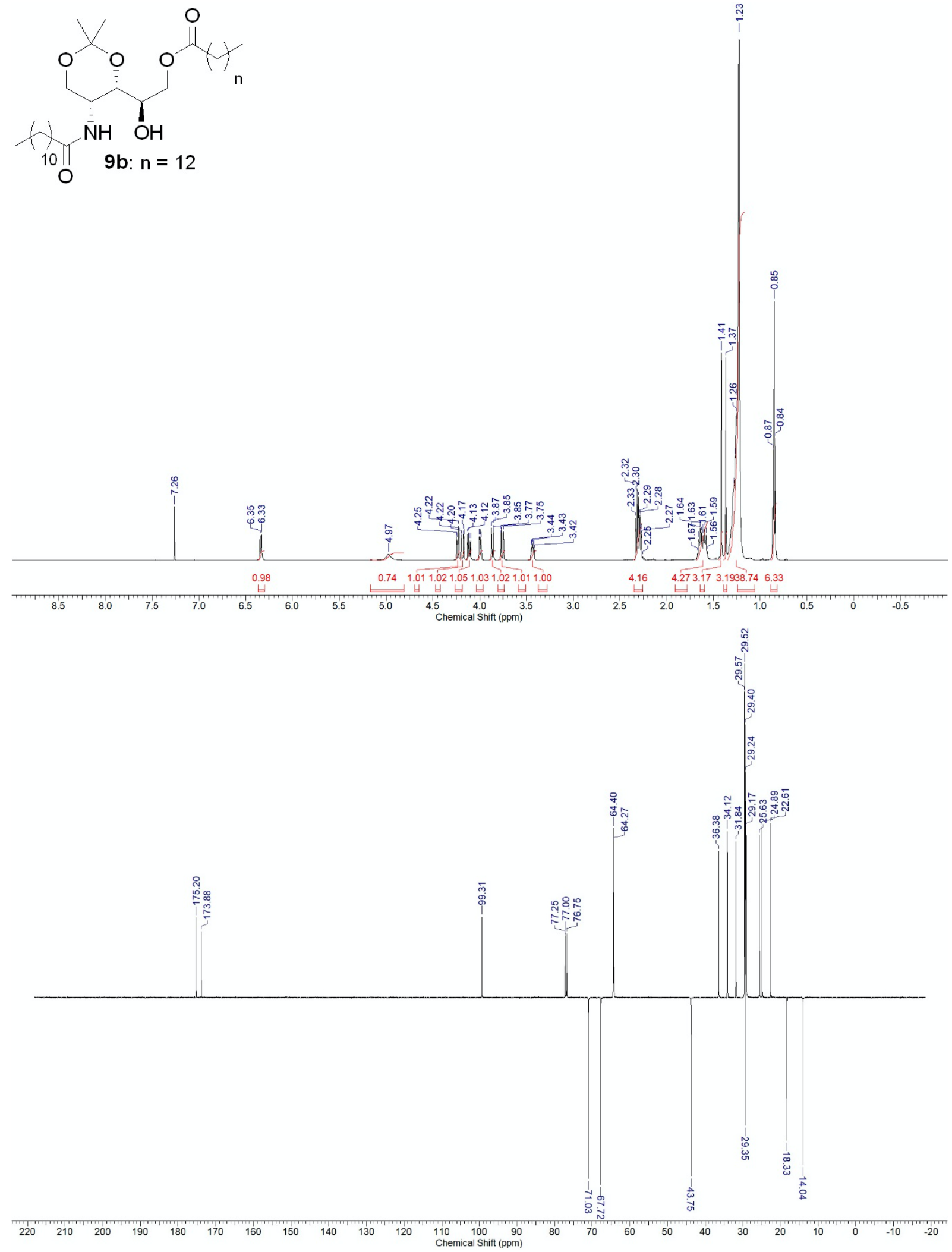


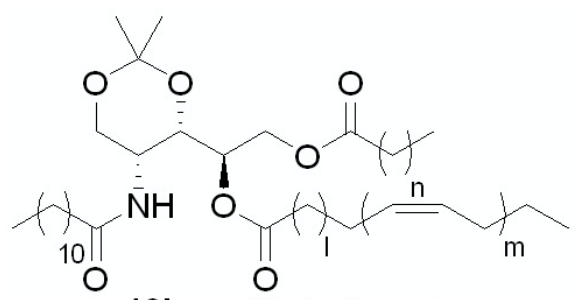

19b: $n=12, I=1, m=2$
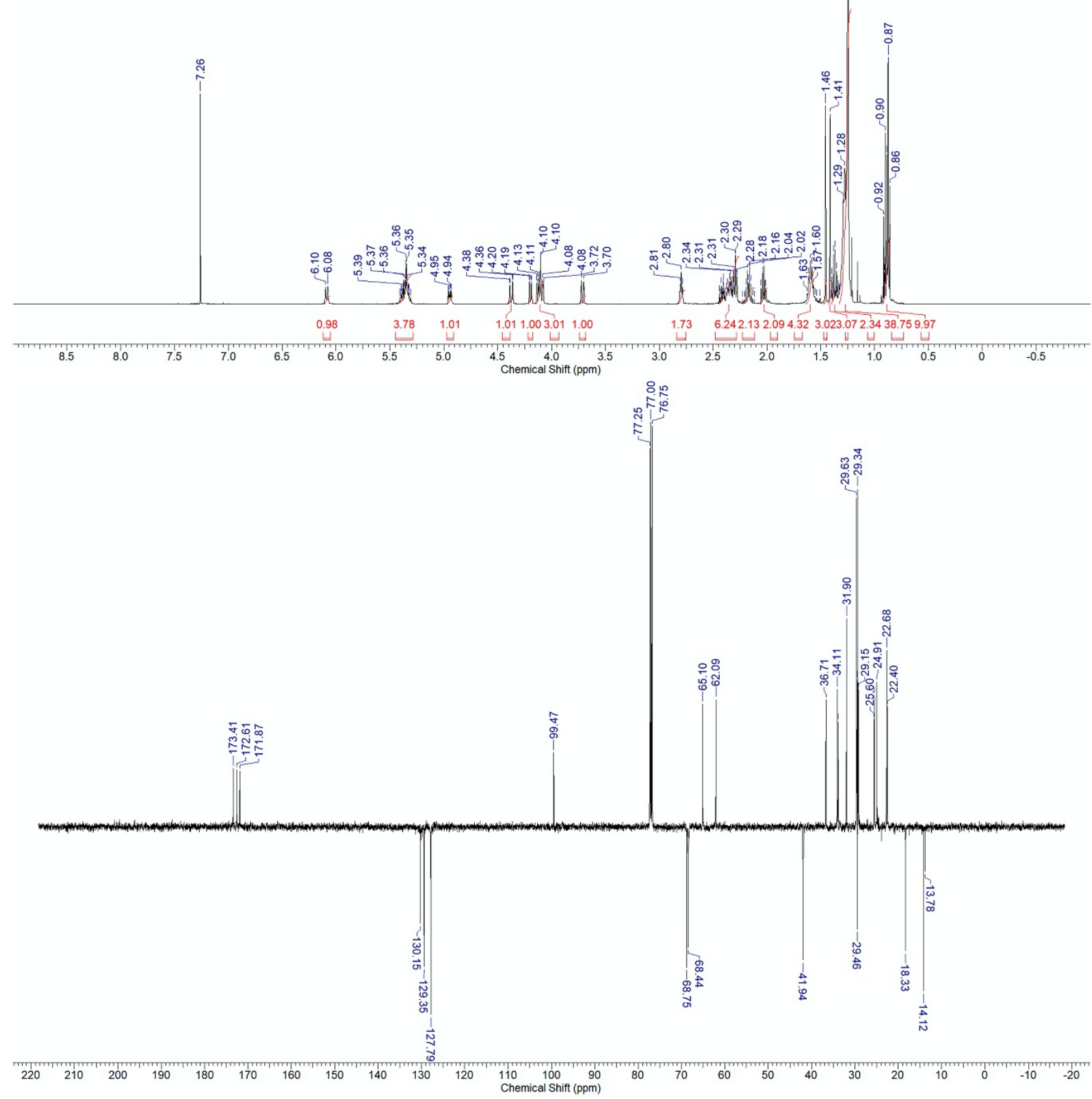

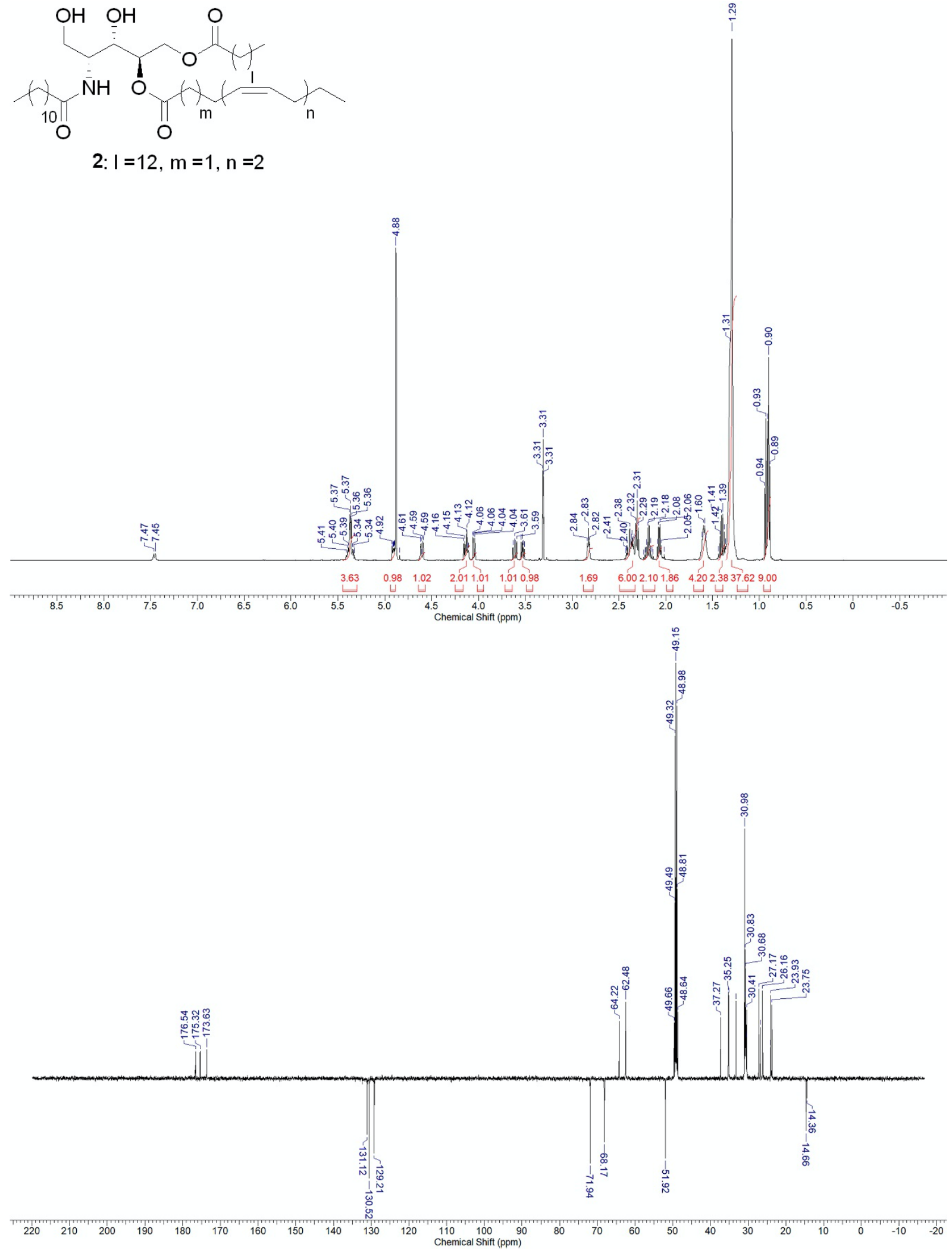
COSY of 2

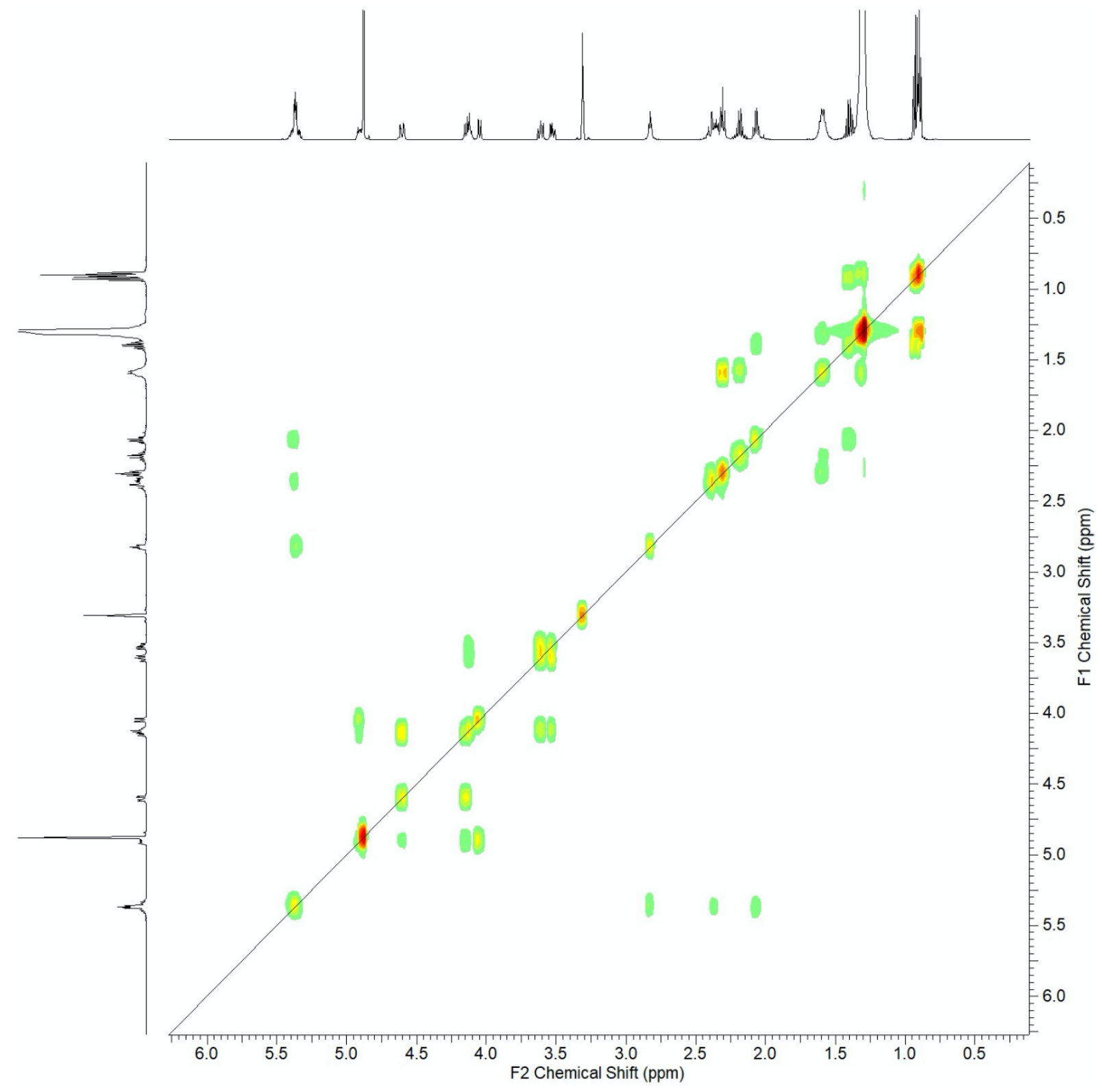


$\mathrm{HMBC}$ of $\mathbf{2}$

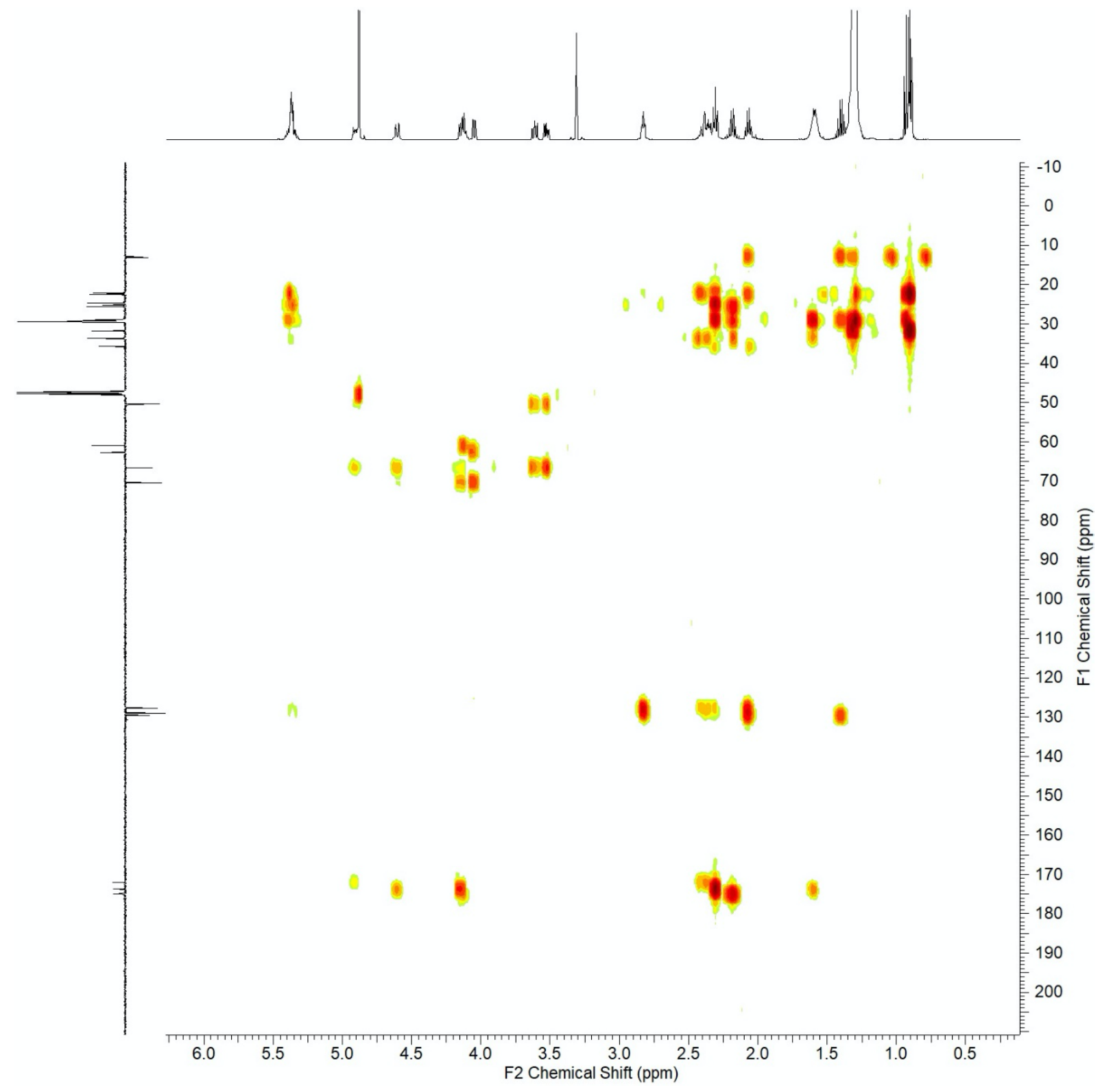


HSQC of 2

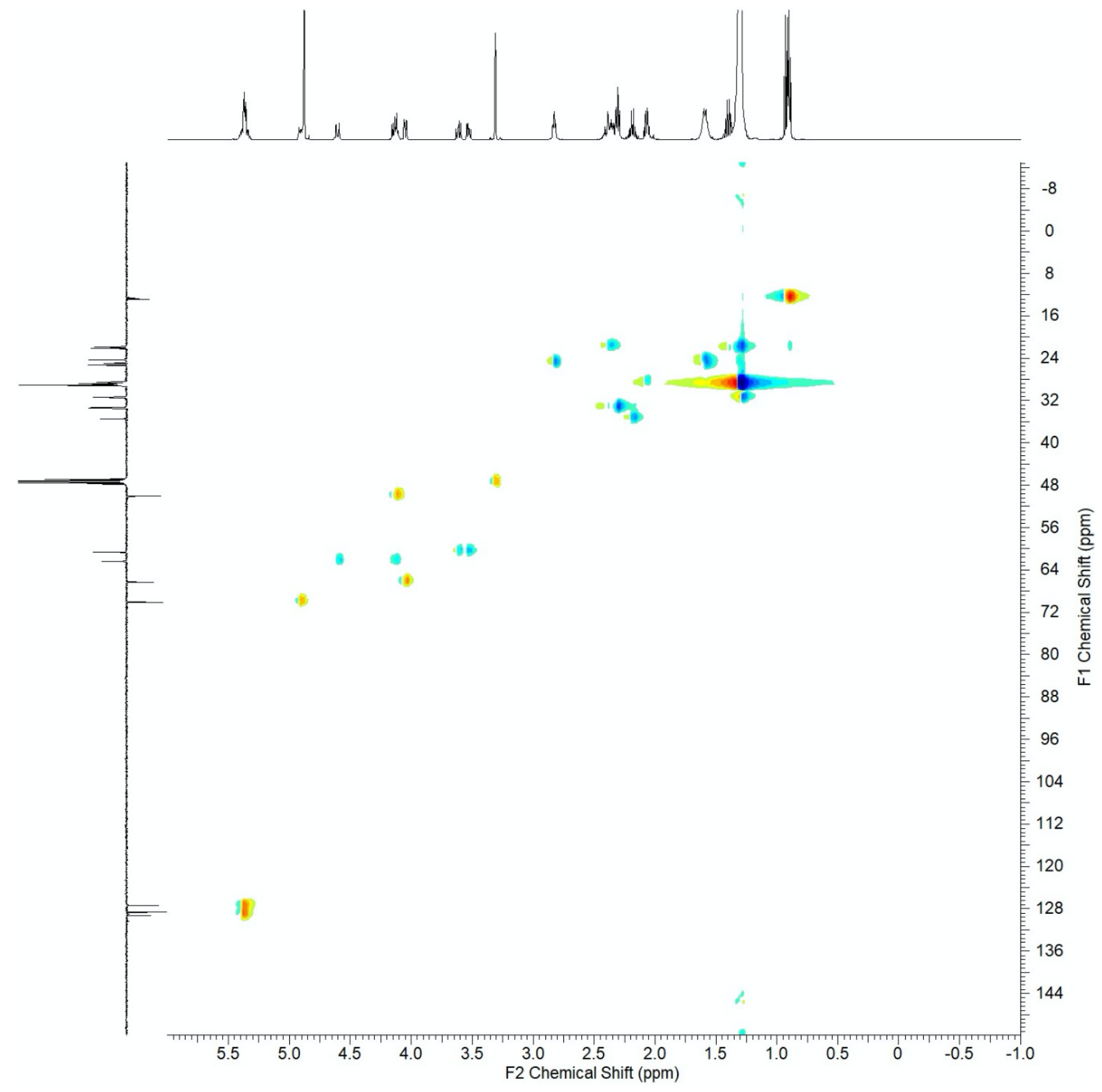



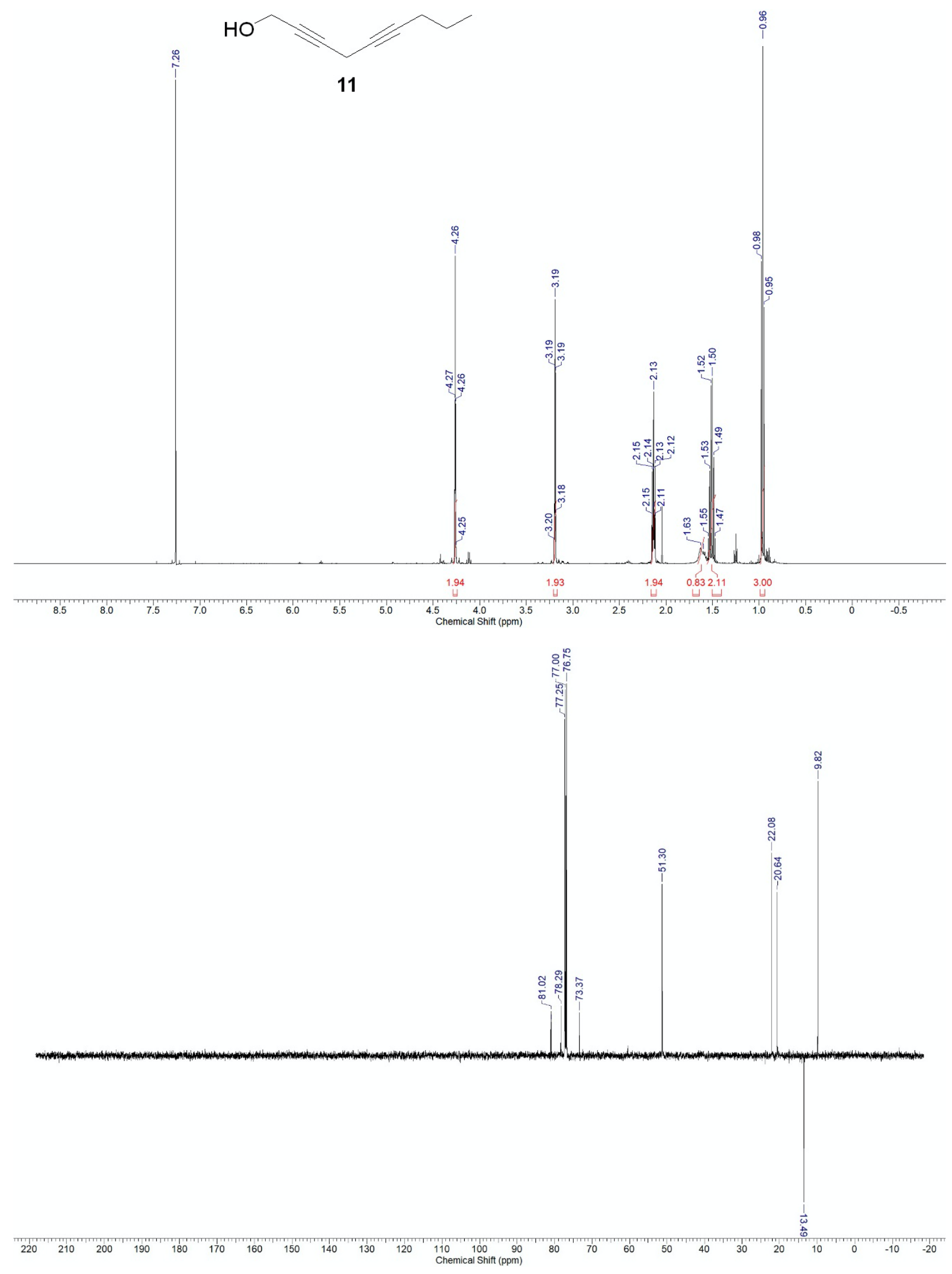


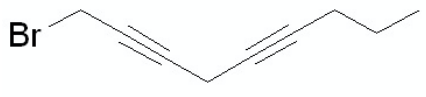

12
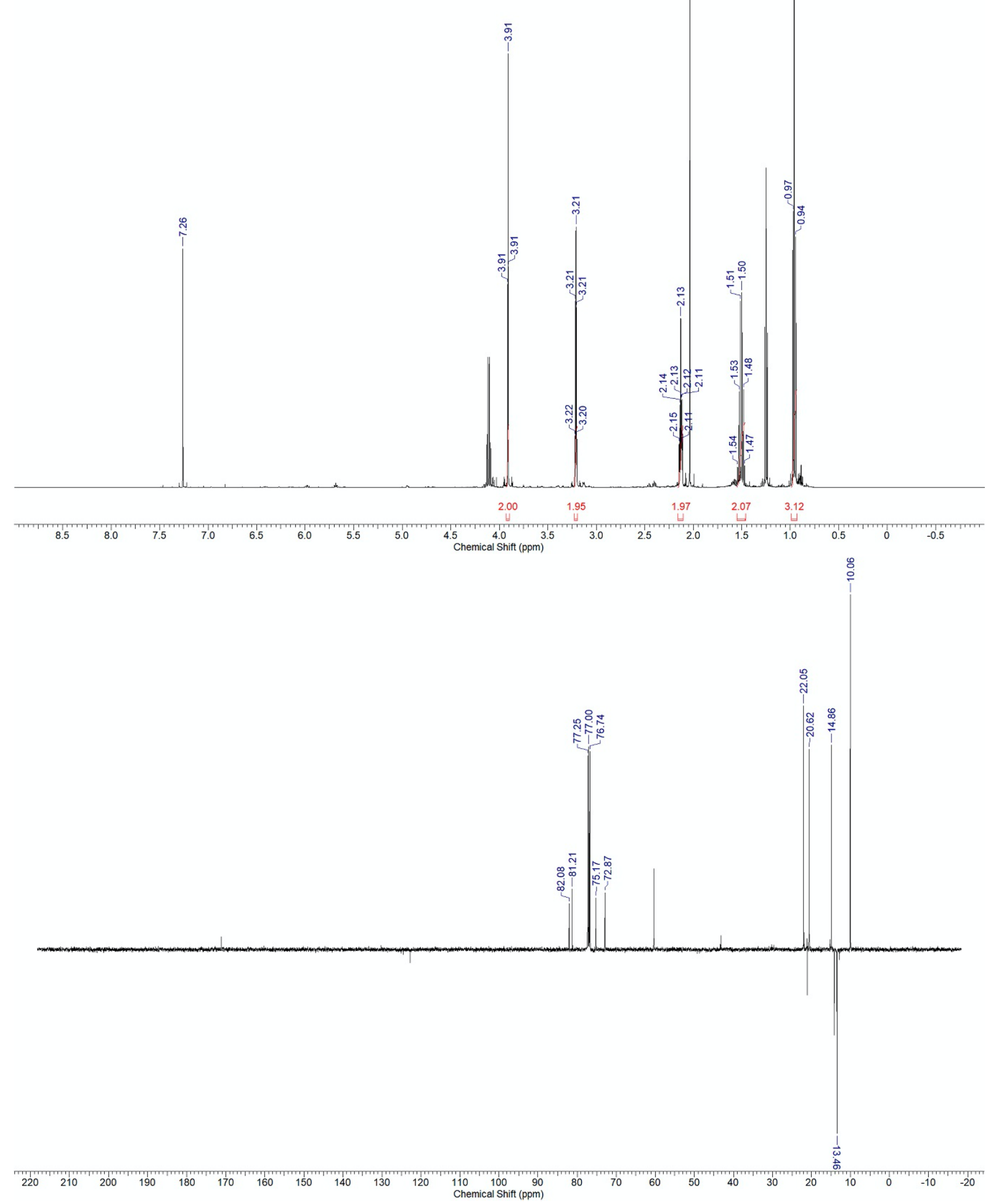

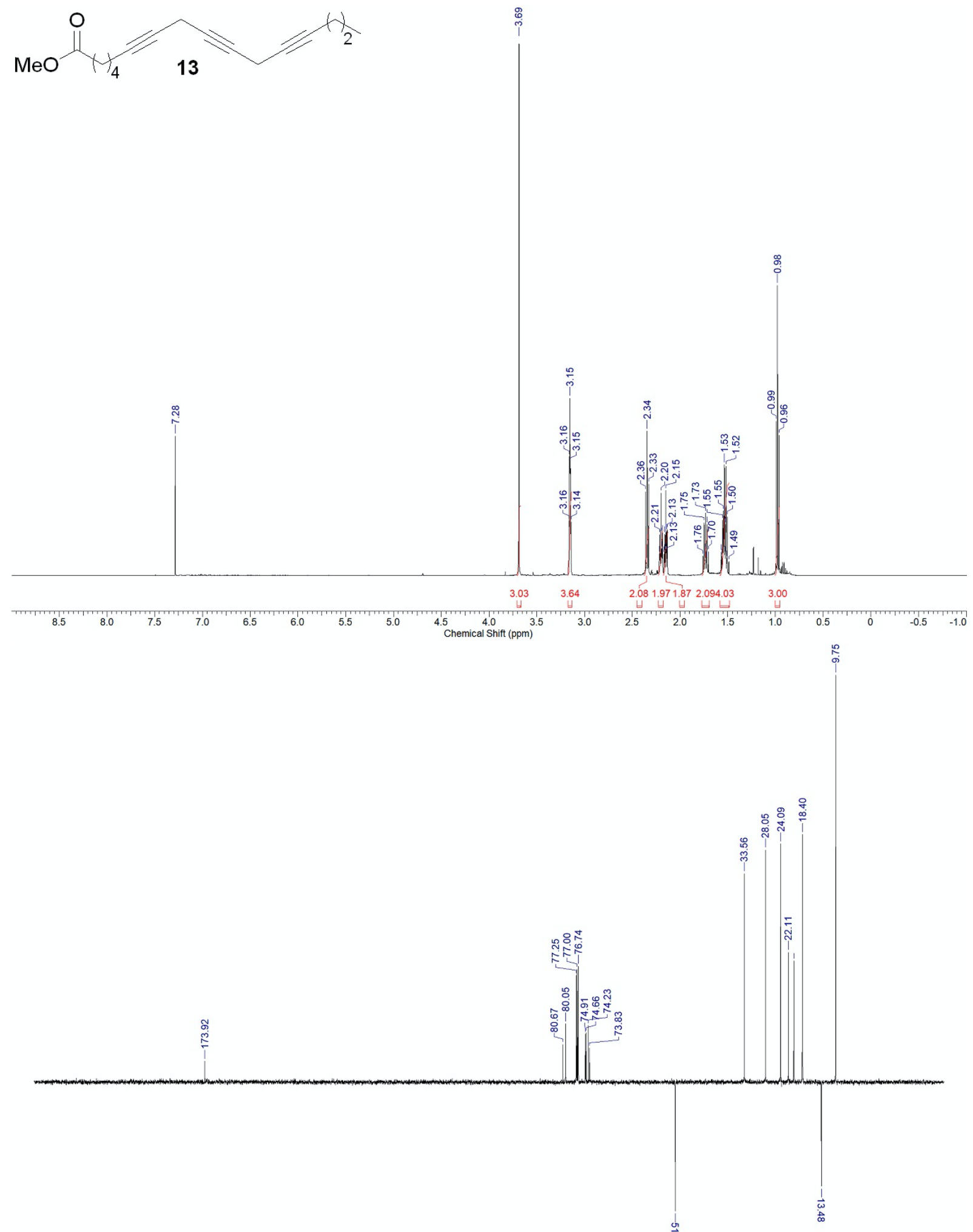

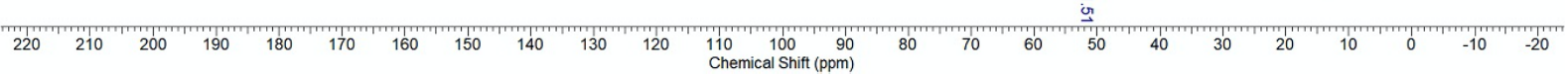



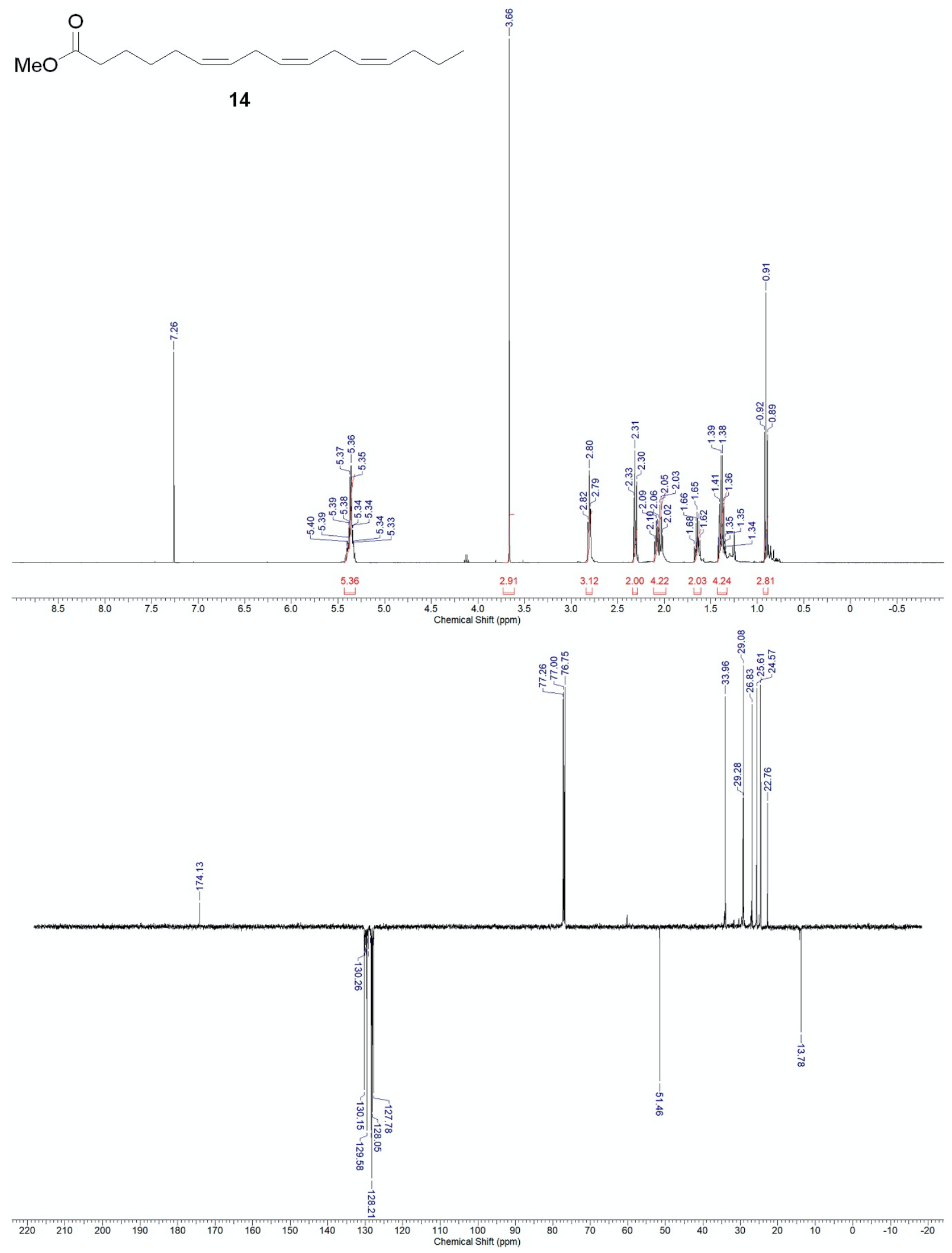
<smiles>CCC/C=C/C/C=C/C/C=C/CCCCC(=O)O</smiles>

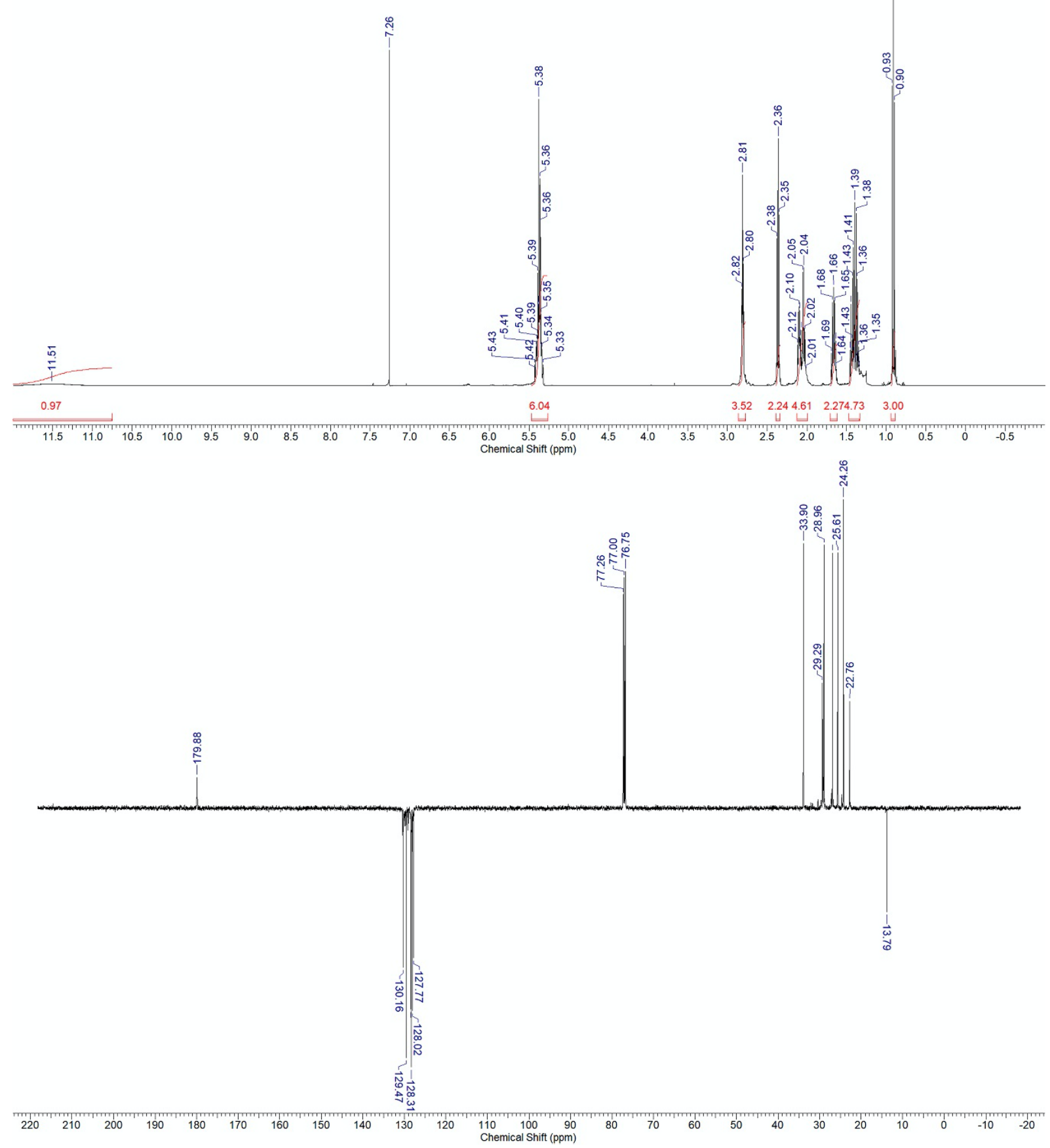


<smiles>COC(=O)C#CCC#N</smiles>

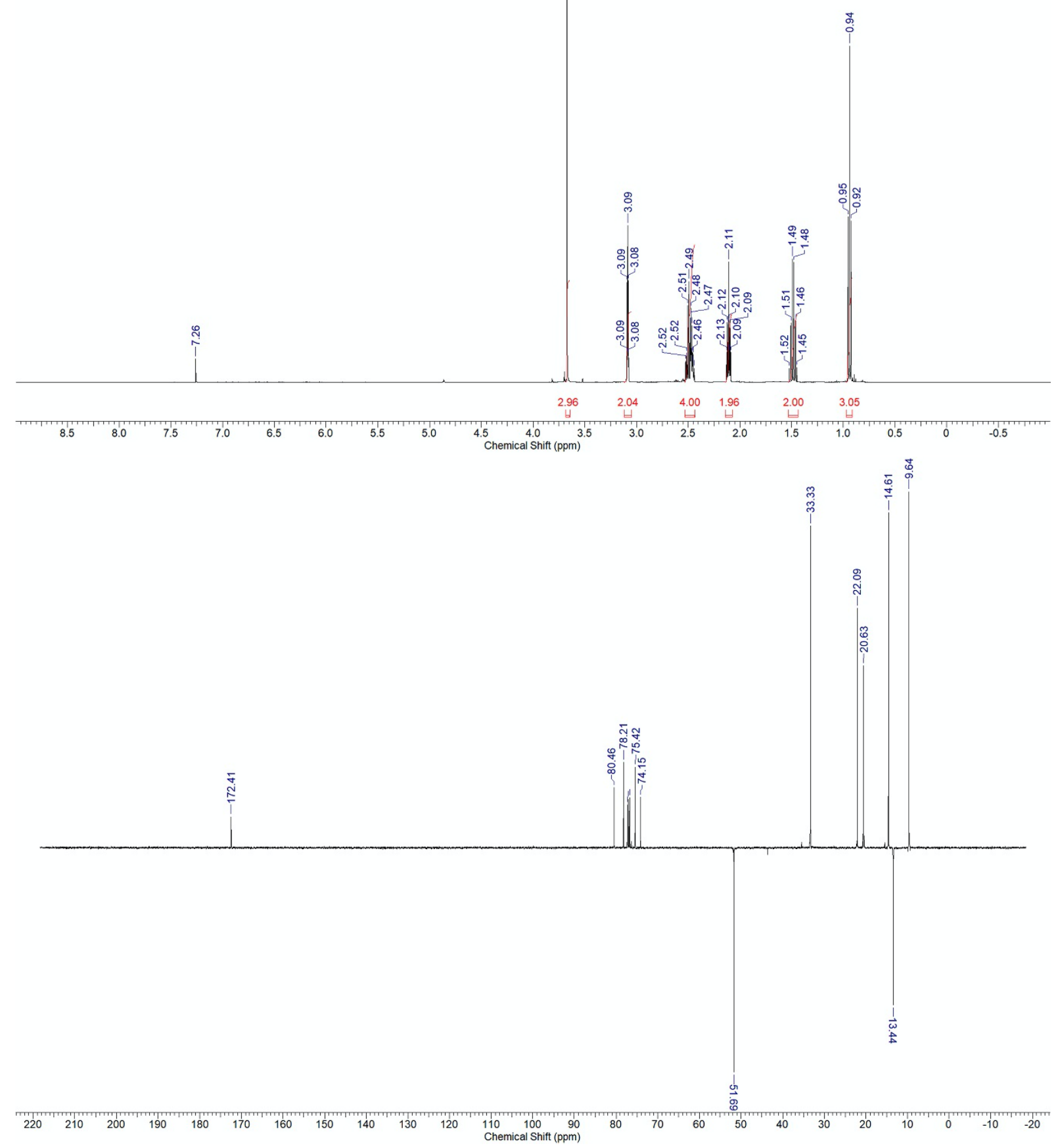



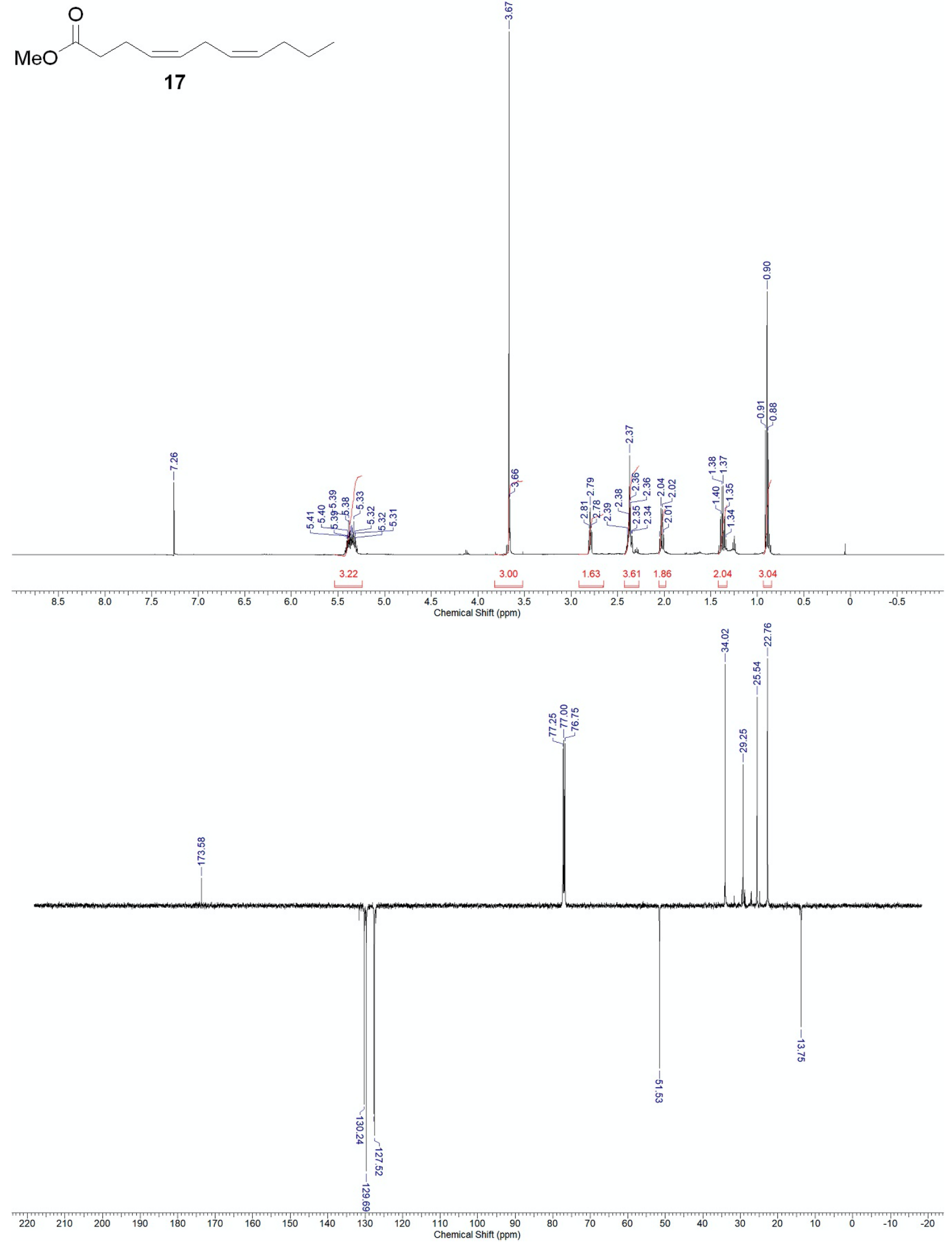

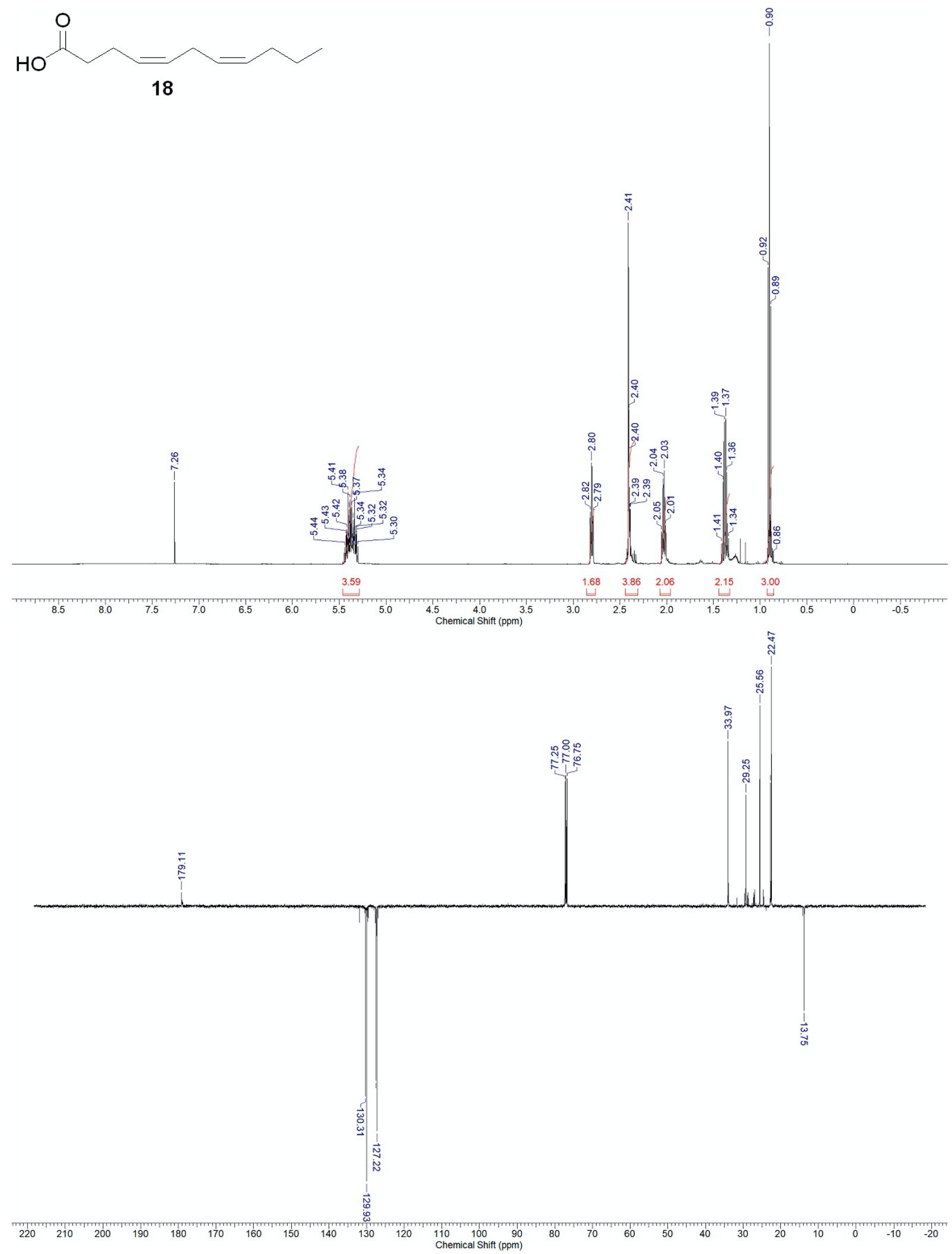

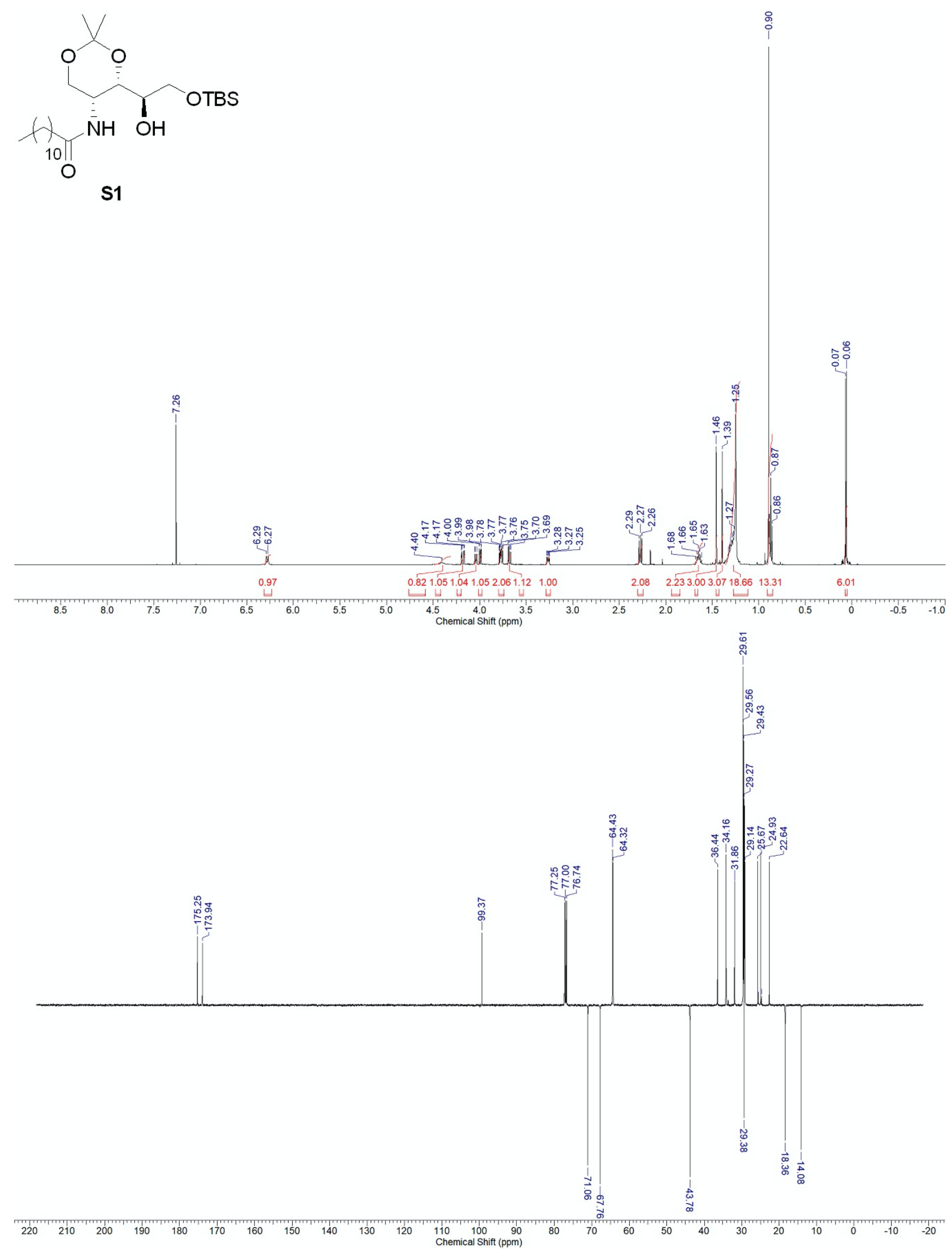

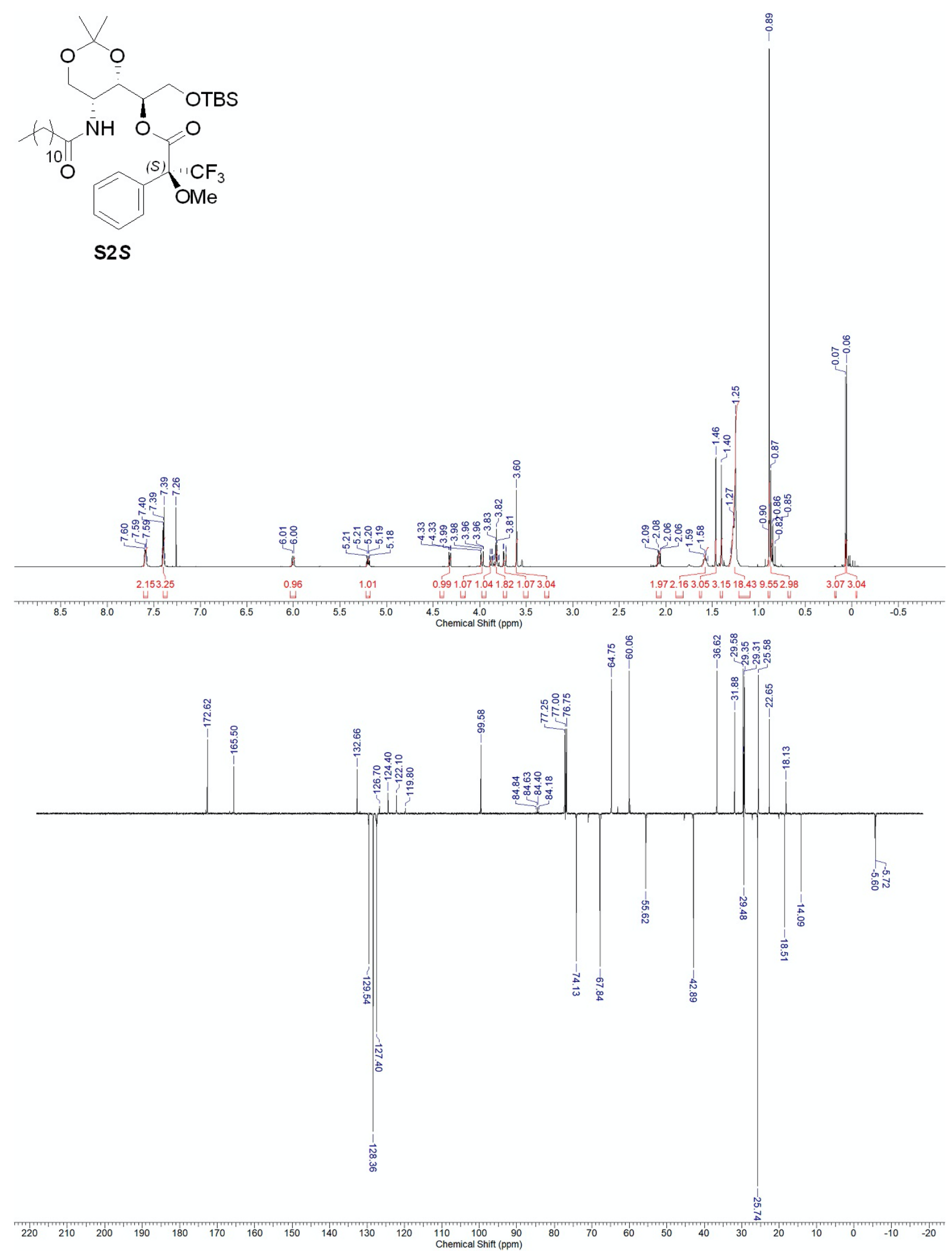


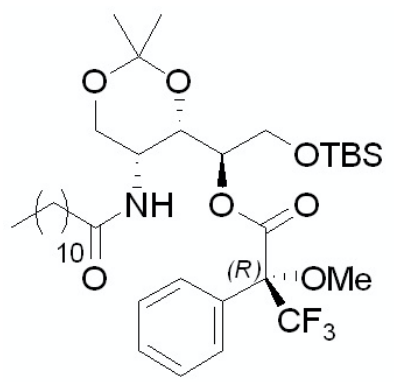

S2R
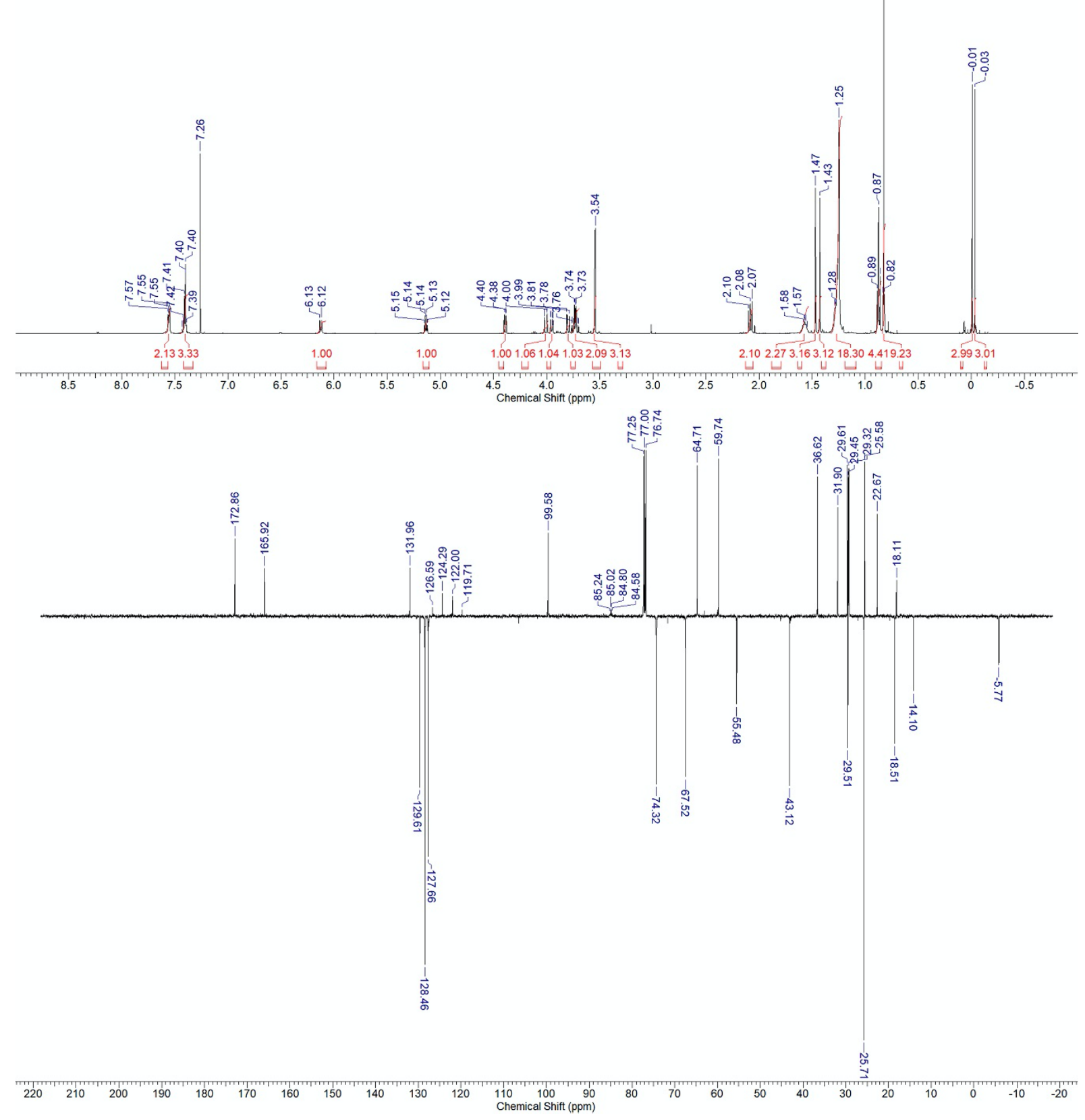


\section{Cell culture conditions and inhibition of cell growth}

\section{Cell culture conditions and stock solutions}

518A2 (Department of Radiotherapy and Radiobiology, University Hospital Vienna) human melanoma cells, HCT-116 (ACC-581) human colon carcinoma cells, as well as its p53 knockout mutant cell line HCT-116 ${ }^{\mathrm{p} 53-/}$, HeLa human cervix carcinoma, U87 human glioblastoma and MCF-7 human breast carcinoma cells were grown in Dulbecco's Modified Eagle Medium (DMEM; Biochrom) supplemented with $10 \%(\mathrm{v} / \mathrm{v})$ fetal bovine serum (FBS; Biochrom) and 1\% (v/v) Antibiotic-Antimycotic solution (Gibco). The cells were incubated at $37{ }^{\circ} \mathrm{C}, 5 \% \mathrm{CO}_{2}, 95 \%$ humidified atmosphere and were serially passaged following trypsinisation by using 0.05\% trypsin/0.02\% EDTA (w/v; Biochrom GmbH, Berlin, Germany). Mycoplasma contamination was frequently monitored, and only mycoplasma-free cultures were used.

\section{Inhibition of cell growth (MTT-assay) ${ }^{3}$}

The cytotoxic effect upon treatment with bathymodiolamides A (1) and B (2) for $72 \mathrm{~h}$ was determined by standard MTT assays. The tetrazolium salt 3-(4,5-dimethylthiazol-2-yl)-2,5-diphenyltetrazolium bromide (MTT; abcr) is reduced by viable cells to a violet, water-insoluble formazan. 518A2 melanoma cells, colon carcinoma cells HCT-116 and HCT-116 ${ }^{\text {p53-/- }}$ and HeLa cervix carcinoma cells $\left(5 \times 10^{4}\right.$ cells $\mathrm{mL}^{-}$ $1,100 \mu \mathrm{L} /$ well), as well as U87 and MCF-7 cells $\left(10 \times 10^{4}\right.$ cells $\mathrm{mL}^{-1}, 100 \mu \mathrm{L} /$ well $)$ were seeded in 96-well tissue culture plates and cultured for $24 \mathrm{~h}$ at $37{ }^{\circ} \mathrm{C}, 5 \% \mathrm{CO}_{2}$ and $95 \%$ humidity. After treatment with the test compounds $\mathbf{1}$ and $\mathbf{2}$ (stock solutions $10 \mathrm{mM}$ in DMSO and freshly diluted appropriately with sterile Milli-Q water) incubation of cells was continued for $72 \mathrm{~h}$. Blank and solvent controls were treated identically. After addition of a $5 \mathrm{mg} \mathrm{mL}^{-1} \mathrm{MTT}$ stock solution in phosphate buffered saline (PBS), microplates were incubated for $2 \mathrm{~h}$ at $37^{\circ} \mathrm{C}$, centrifuged at $300 \mathrm{~g}, 4^{\circ} \mathrm{C}$ for $5 \mathrm{~min}$ and the supernatant was discarded. The precipitate of formazan crystals was then redissolved in a $10 \%(\mathrm{w} / \mathrm{v})$ solution of sodium dodecylsulfate (SDS; Carl Roth) in DMSO containing $0.6 \%$ (v/v) acetic acid. To ensure complete dissolution of the formazan, the microplates were incubated for at least $1 \mathrm{~h}$ in the dark. Finally, the absorbance at $\lambda=570$ and $630 \mathrm{~nm}$ (background) was measured using a microplate reader (Tecan F200). All experiments were carried out in quadruplicate and the percentage of viable cells was calculated as the mean \pm SD with controls set to $100 \%$. The determined $I C_{50}$ (inhibitory concentration) values are shown in table 1.

Table 2. Inhibitory concentrations $\mathrm{IC}_{50}[\mu \mathrm{M}]$ of $(2 R, 3 S, 4 R)$-bathymodiolamides $\mathrm{A} \mathbf{1}$ and $\mathrm{B} \mathbf{2}$ when applied to

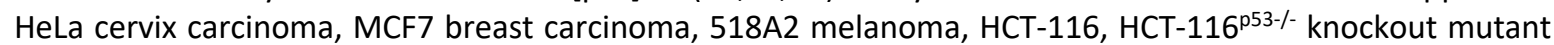
colon carcinoma and U87 glioblastoma cells. Values are the means \pm SD determined in four independent experiments and derived from dose-response curves after $72 \mathrm{~h}$ incubation using the MTT assay.

\begin{tabular}{|c|c|c|c|c|c|c|}
\hline \multicolumn{7}{|c|}{$\mathrm{IC}_{50}(\mu \mathrm{M})$} \\
\hline & HeLa & MCF7 & 518A2 & HCT-116 & HCT-116 ${ }^{\text {p53-/- }}$ & U87 \\
\hline 1 & $>50$ & $>50$ & $>50$ & $>50$ & $>50$ & $>50$ \\
\hline 2 & $>50$ & $>50$ & $>50$ & $>50$ & $>50$ & $>50$ \\
\hline
\end{tabular}

Neither of the two synthetic bathymodiolamides $\mathbf{1}$ and $\mathbf{2}$ showed a cytotoxic effect on the six human cell lines in the concentration range up to $50 \mu \mathrm{M}$ 


\section{References}

(1) Andrianasolo, E. H.; Haramaty, L.; McPhail, K. L.; White, E.; Vetriani, C.; Falkowski, P.; Lutz, R. Bathymodiolamides A and B, Ceramide Derivatives from a Deep-Sea Hydrothermal Vent Invertebrate Mussel, Bathymodiolus thermophilus. J. Nat. Prod. 2011, 74, 842-846.

(2) Ohtani, I.; Kusumi, T.; Ishitsuka, M. O.; Kakisawa, H. Absolute configurations of marine diterpenes possessing a xenicane skeleton. An application of an advanced mosher's method. Tetrahedron Lett. 1989, 30, 3147-3150.

(3) Mosmann, T. J. Rapid colorimetric assay for cellular growth and survival: Application to proliferation and cytotoxicity assays. J. Immunol. Methods, 1983, 65, 55-63 